\title{
Indigenous Involvement in the Canadian Species at Risk Recovery Process
}

\author{
by
}

Cassandra J. Hill

A thesis submitted to the Faculty of Graduate and Postdoctoral Affairs in partial fulfillment of the requirements for the degree of

Master of Science

in

Biology

Carleton University

Ottawa, Ontario

(C) 2018, Cassandra J. Hill 


\section{Abstract}

Many countries, including Canada, are beginning to officially recognize the vital roles of Indigenous Peoples in threatened species recovery. To determine whether official recognition is translating into actual involvement of Indigenous Peoples in threatened species recovery planning, I examined recovery strategies and management plans for threatened species under the Canadian Species at Risk Act (SARA). I scored each document for the level of involvement with Indigenous Peoples. I analyzed the data using permutation-based ANOVAs and post hoc pairwise permutation tests to determine the impact of region, taxonomic group, and responsible agency on scores. Fifty two percent of documents suggested no Indigenous involvement, despite a legal requirement to consult. Documents for species in central Canada and Quebec indicated significantly lower levels of involvement than in other regions. Documents for less iconic taxonomic categories such as mosses and arthropods indicated lower levels of involvement than for fish, mammals and birds. These regional and taxonomic discrepancies may suggest priorities for immediate improvement in involving Indigenous Peoples in conservation efforts.

Key Words: Indigenous Peoples, First Nations, Consultation, Co-management, Species at Risk, Recovery Strategy, Management Plan, Content Analysis, Expert Elicitation, Aboriginal Traditional Knowledge (ATK), Traditional Ecological Knowledge (TEK), Conservation 


\section{Acknowledgements}

I would like to thank my committee members: Joseph Bennett, Richard Schuster, Steve Cooke, Zoe Todd (Carleton University), and Jeremy Kerr (University of Ottawa). I would also like to thank all those that helped with the expert elicitation of my scoring system: Richard Schuster, Steve Cooke, Zoe Todd, Andrea Reid (Carleton University), Jeremy Kerr (University of Ottawa), Henry Lickers (Mohawk Council of Akwesasne), Nick Reo (Dartmouth College), and Donna Hurlburt (COSEWIC, Acadia University), and all authors/contributors of species recovery documents who offered information on the consultation process. I would also like to thank my friends and family for their support throughout my project. In addition, I'd like to thank The Mohegan Tribe of Uncasville, Connecticut for their financial and spiritual support, and the traditional knowledge they've taught me throughout my life.

This thesis contains information licensed under the Open Government License Canada. 
Table of Contents

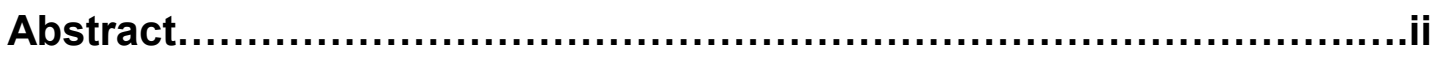

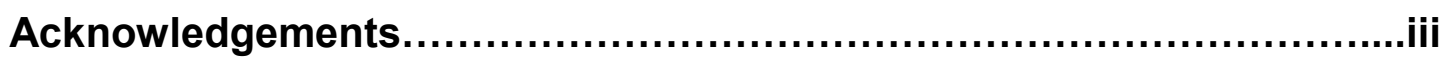

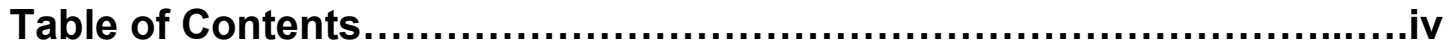

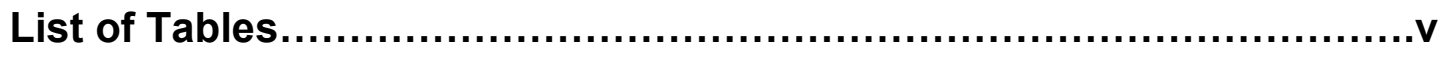

List of Figures ..........................................................................

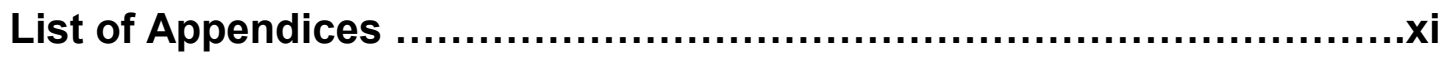

CHAPTER ONE $\quad$ GENERAL INTRODUCTION ..........................

CHAPTER TWO INDIGENOUS INVOLVEMENT IN THE CANADIAN SPECIES AT RISK RECOVERY PROCESS...........8

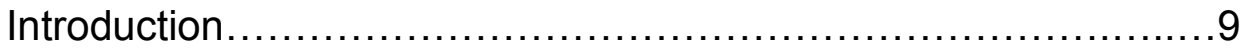

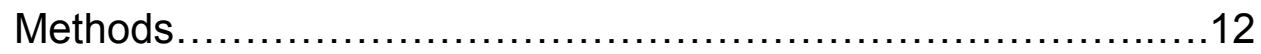

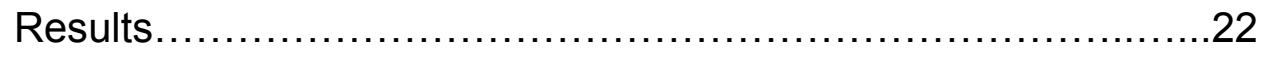

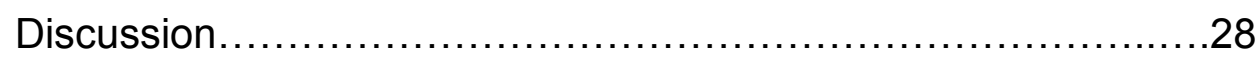

CHAPTER THREE $\quad$ GENERAL SUMMARY ...............................38

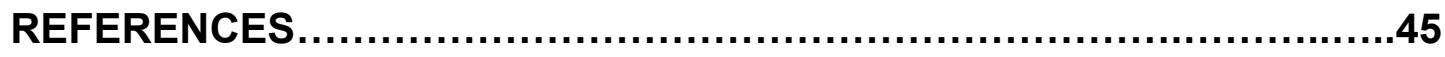

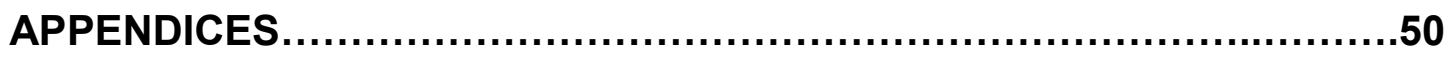

A: Scoring system............................................... 50

B: Additional figures and analysis................................52 


\section{List of Tables}

Table A1. Percentage of Indigenous declined involvement by region.

Table A2. Percentage of zeros scored for recovery strategies and management plan in each regional category. Species whose ranges do not overlap with Indigenous lands and "declined involvement" zeros removed $(n=477)$.

Table A3. Percentage of zeros scored for recovery strategies and management plans in each taxonomic category. Species whose ranges do not overlap with Indigenous lands and "declined involvement" zeros removed $(n=477)$.

Table A4. Results of a permutation based ANOVA testing differences in mean scores, showing the relationship between region and document type (management plan and recovery strategy).

Table A5. Results of a permutation based ANOVA testing differences in mean scores, showing the relationship between taxonomic category and document type (management plan and recovery strategy).

Table A6. Results of a permutation based ANOVA testing differences in mean scores, showing the relationship between taxonomic category and region. 
Table A7. Results of a permutation based ANOVA testing for differences in mean scores among regional categories. Differences among individual regional pairs are shown in figure 2 .

Table A8. Results of a permutation based ANOVA testing differences in mean scores, among taxonomic categories. Differences among individual taxonomic pairs are shown in figure 3.

Table A9. Results of a permutation based ANOVA showing the relationship between score and agency. Agency was not included in main model as many taxonomic groups are not represented by certain agencies. Differences among individual agency pairs are shown in figure A2.

Table A10. Results of a permutation based ANOVA testing differences in mean scores, showing the relationship between region and responsible agency.

Table A11. Results of a pairwise permutation test showing significant differences between groupings of responsible agencies and regions.

Table A12. Results of a permutation based ANOVA testing differences in mean scores, showing the relationship between region and taxonomic group after all multi-regional plans had been eliminated. 
Table A13. Results of a permutation based ANOVA testing differences in mean scores, among regional categories after all multi-regional plans had been eliminated. Differences among individual regional pairs are shown in figure A4.

Table A14. Results of a permutation based ANOVA testing differences in mean scores among taxonomic categories after all multi-regional plans had been eliminated. Differences among individual taxonomic pairs are shown in figure A5. 


\section{List of Figures}

Figure 1. Flow chart representing the steps taken to clean data for final analysis.

Figure 2. Mean score for evidence of Indigenous involvement in recovery strategies and management plans by region ( \pm standard error $(\mathrm{SE}))$. The letters above each bar represent groupings based on significant differences in pairwise permutation tests. Western region (Pacific Ocean and British Columbia: $n=131$ ), central region (Alberta, Saskatchewan and Manitoba: $n=68)$, Ontario $(n=134)$, Quebec $(n=64)$, eastern region (Nova Scotia, New Brunswick, Prince Edward Island, Newfoundland and Labrador, and the Atlantic Ocean: $n=56$ ), northern/arctic region (Yukon, Nunavut, Northwest Territories, and the Arctic Ocean: $n=24)$.

Figure 3. Mean score for evidence of Indigenous involvement in recovery strategies and management plans by taxonomic category ( \pm standard error $(\mathrm{SE})$ ). The letters above each bar represent groupings based on significant differences in pairwise permutation tests. Amphibians $(n=20)$, arthropods $(n=34)$, birds $(n=$ 123), fish $(n=44)$, lichens $(n=12)$, mammals $(n=48)$, molluscs $(n=14)$, mosses $(n=20)$, plants $(n=123)$, reptiles $(n=39)$.

Figure A1. Number of recovery strategies and management plans included in each stage of data analysis. Data include all recovery strategies and management plans of species whose ranges overlap with Indigenous lands. 
Duplicates are defined as any species document that was counted more than once to represent multiple regions of species range.

Figure A2. Mean score for evidence of Indigenous involvement in recovery strategies and management plans by agency ( \pm standard error $(\mathrm{SE})$ ).. The letters above each bar represent groupings based on significant differences in pairwise permutation tests. Environment and Climate Change Canada $(n=353)$, Fisheries and Oceans Canada ( $n=73)$, Parks Canada $(n=51)$.

Figure A3. Scatter plot with trend line showing average score of recovery documents versus the year they were published, starting with the first documents published in 2006. $R^{2}$ and $p$-value based on an ordinary least squares regression shown within chart.

Figure A4. Mean score for evidence of Indigenous involvement in recovery strategies and management plans by region ( \pm standard error $(\mathrm{SE}))$., after all multi-regional plans had been eliminated. The letters above each bar represent groupings based on significant differences in pairwise permutation tests. Species whose ranges do not overlap with Indigenous lands removed, "declined involvement" species removed. Western region $(n=104)$, central region $(n=35)$, Ontario $(n=80)$, Quebec $(n=9)$, eastern region $(n=24)$, northern/arctic region $(n=$ $5)$. 
Figure A5. Mean score for evidence of Indigenous involvement in recovery strategies and management plans by taxonomic category ( \pm standard error $(\mathrm{SE})$ ). The letters above each bar represent groupings based on significant differences in pairwise permutation tests. Species whose ranges do not overlap with Indigenous lands removed, "declined involvement" species removed, and duplicates from multi-regional species removed. Amphibians $(n=13)$, arthropods $(n=21)$, birds $(n=26)$, fish $(n=28)$, lichens $(n=9)$, mammals $(n=33)$, molluscs $(n=14)$, mosses $(n=10)$, plants $(n=85)$, reptiles $(n=18)$. 


\section{List of Appendices}

Appendix A: Scoring System Details

Appendix B: Additional Analysis (figures and tables) 


\section{CHAPTER ONE}

\section{GENERAL INTRODUCTION}


Cooperative management for conservation between the federal/provincial governments and Indigenous Peoples can be beneficial to both parties. Not only can Indigenous Peoples provide information and suggestions based on hundreds or thousands of years of successes and failures in maintaining ecosystems (Gadgil et al.,1993), but through involvement in conservation efforts, Aboriginal traditional knowledge (ATK) is often written down and therefore preserved for future generations (Horstman \& Whightman, 2001). Conservation has approached a new age where Indigenous knowledge is becoming increasingly valued as a result of the ongoing social movement to respect Indigenous rights (Colchester, 2004). However, the knowledge of Indigenous Peoples is often still looked down upon as being less accurate and therefore less valuable than Western science. This has to do with the fact that most ATK is not seen as scientific information, so it is not considered legitimate in comparison to Western science (Buchanan, 2016). Partnerships between scientists and Indigenous Peoples may provide the best outcomes for conservation (Alcorn, 1993), but scientists must first let go of their uncertainty concerning the validity of ATK. In addition, it must be recognized that Indigenous Peoples have an essential role in the protection and maintenance of the ecosystems they remain connected to. By not properly consulting Indigenous Peoples on conservation matters, there is a risk of missing out on crucial information and disregarding Indigenous rights. The Canadian Species at Risk Act (SARA) has a stated goal of conserving species at risk and avoiding extirpation or extinction (SARA, 2002). In SARA, it is 
stated that Aboriginal Traditional Knowledge (ATK) should be taken into account in recovery planning for species at risk, and any Indigenous Peoples who may be affected by the recovery process should be consulted (SARA, 2002). However, clear guidelines for consultation and involvement of Indigenous Peoples are lacking. In regard to involving Indigenous Peoples in recovery planning, sections 39.1, 48.1, and 66.1 of The Act simply state that recovery strategies, action plans, and management plans (respectively) "to the extent possible...must be prepared in cooperation with every aboriginal organization that the competent minister considers will be directly affected by [the plan/strategy]" (SARA, 2002). SARA has established the National Aboriginal Council on Species at Risk, an advisory council to the Minister, but the part this Council plays is unclear as it is rarely mentioned within recovery documents. In addition, there are no published guidelines that describe how this effort to seek cooperation should be carried out, leaving interpretation of the phrase "to the extent possible" to the authors of the documents.

The definition of consultation within the Canadian Species at Risk Act (2002) stated in Section 6.1 of The Act is "...the government must inform Aboriginal organizations about the recovery process and provide them with adequate information to assess the situation and respond to the request to participate in a timely manner." Therefore, simply providing information about the recovery of a species at risk to an Indigenous organization with a request for input is enough to fulfil the duty to consult. These parameters for the involvement of Indigenous 
Peoples are subject to liberal interpretation, and such ambiguity may allow efforts that are unlikely to invoke a response from Indigenous Peoples.

Various factors may contribute to Indigenous Peoples rejecting opportunities for involvement, such as confusion about the Indigenous involvement process and cultural barriers. Some confusion is derived from the fact that there is no single established process for Indigenous Peoples to ensure that their knowledge and rights are being utilized and respected in the species at risk recovery process (Maritime Aboriginal Peoples Council, 2014). Cultural barriers are seen in the form of language, which can pose a problem if the name Indigenous people call a species is the traditional rather than the common name. Ens et al. (2016) describes one such situation in Australian conservation efforts where interviews with Elders revealed several different traditional names for various plants and animals. In this case, appropriate accommodation is necessary for Indigenous Peoples to be able to cooperate in conservation measures.

Declination of involvement in recovery planning may also be because Indigenous Peoples are aware of the lack of value and consideration given to traditional knowledge. Some tribes such as the Klamath Tribes of southeastern Oregon have made a complete transformation to "scientize" their traditional knowledge in order for their voices to be taken seriously in the conservation of culturally significant fish (Buchanan, 2016). However, not all tribes have the means to do this, or may refuse to do this for risk of de-authenticating their traditional knowledge by forcing it into framework that eliminates its spiritual meaning. 
Strained Indigenous-government relationships may cause Indigenous Peoples to reject the authority of the government over natural resources, and therefore reject opportunities to collaborate with conservation measures. Castro \& Nielsen (2001) describe cultural livelihood, resistance of appropriation, and preservation of cultural identity as a reason for the establishment of co-management, but these could also all be seen as reasons to avoid involvement with the government. Overall, involving Indigenous Peoples within western conservation has many complications, but the current Indigenous involvement process in Canadian recovery planning under SARA does not allow for most of them. My study investigates the level of Indigenous involvement and consultation in creating management documents for recovery of Canadian species at risk. Specifically, it addresses the following questions:

1. What is the average level of involvement of Indigenous Peoples in species at risk recovery processes in Canada?

2. Does the region in which a species is found affect the level of involvement of Indigenous Peoples present in that species' recovery process? If so, what region(s) have more evidence of involvement of Indigenous Peoples?

3. Does the taxonomic category of a species affect the level of involvement of Indigenous Peoples present in that species' recovery process? If so, which taxonomic groups have more evidence of involvement of Indigenous Peoples? 
4. Has the level of involvement of Indigenous Peoples changed over time based on the publication dates of recovery documents?

5. Does the agency under which the species' recovery document was written affect the level of involvement of Indigenous Peoples?

The government of Canada has indicated that greater inclusion of Indigenous Peoples in decision-making is a national priority (Department of Justice Canada, 2018). Although this can be viewed as a positive step, it is recognized a lot needs to be done in order to make this priority a reality (Coates, 2017). We posed the above questions to help guide the process of stronger partnerships between the government and Indigenous Peoples for species at risk management.

There is also a lack of research revealing the specific areas in which inclusion of Indigenous Peoples in conservation needs the most improvement. Pinpointing these areas can allow for better implementation and enforcement of specific guidelines for Indigenous co-management in conservation.

In this thesis, I will discuss the importance of involving Indigenous Peoples in conservation, explaining the struggles associated with Indigenous comanagement and cooperation. I will then explain the methods of my context analysis, scoring system development, data processing, and data analysis. I will state the results of my analysis including correlations between the levels of Indigenous involvement and regions in which species are found, and taxonomic category. I will discuss these results in the context of current issues and outline possible explanations for my findings with caveats regarding factors that could 
not be quantified. The results of additional tests, including effects of year and agency on document scores, and effects of region and taxonomic category after the removal of multi-regional recovery plans, are included in the appendices. 
CHAPTER TWO

\section{INDIGENOUS INVOLVEMENT IN THE CANADIAN SPECIES AT RISK RECOVERY PROCESS}




\section{Introduction:}

Indigenous Peoples are not only often looked down upon socially by the general public, but they are also undervalued in the arena of conservation science (Colchester, 2004). Indigenous traditional knowledge and perspectives are often seen by non-Indigenous people as second class information in comparison to western science (Buchanan, 2016), which is likely a root cause of lack of Indigenous involvement in conservation efforts (Walker, 2001).

Canada in particular has had many conflicts between governments (both federal and provincial) and Indigenous Peoples, with some initial positive steps now occurring (Joseph, 2018). The resulting strained relationship may affect the willingness of either or both sides to cooperate on conservation efforts. Indigenous involvement has been neglected in many conservation efforts, such as the Canadian Boreal Forest Agreement in 2010, in which First Nations opinions on the use of their ancestral lands were ignored (Smith, 2015). This disregard for the adequate inclusion of Indigenous perspectives in resource and land management is still happening (Moore et al., 2017), despite the government's legal duty to consult (Haida Nation vs. British Columbia, 2014). The Canadian Species at Risk Act was adopted in 2002 in order to protect and recover Canadian wildlife species (SARA, 2002). The Committee on the Status of Endangered Wildlife in Canada (COSEWIC) first assesses species at risk to be labeled extirpated, endangered, threatened, or special concern, based on factors such as declining ranges or populations and the level of threat to these species' 
existence in the wild in Canada. This is followed by further assessment by the Minister of the Environment and the Canadian Endangered Species

Conservation Council, along with public consultations. If a decision is made for the species to be listed, SARA continues the recovery process with the development of management plans for special concern species and recovery strategies for threatened and endangered species. Action plans are then developed as the next step in the recovery process for these species (SARA, 2002). Three agencies (Environment and Climate Change Canada, Parks Canada, and Fisheries and Oceans Canada) are responsible for managing species at risk and producing recovery documents for them. The complete process is outlined in detail by Mooers et al. (2007, 2010), Findlay et al. (2009) and Raymond et al., (2018).

The legal duty to consult with Indigenous Peoples applies to both COSEWIC and SARA. However, the guidelines on how to include Indigenous Peoples within SARA's recovery processes are vague. For each document (action plans, recovery strategies, and management plans) the Act merely states that Aboriginal organizations must be involved "to the extent possible", and only those organizations that the minister considers likely to be affected by the plan (SARA, 2002, sections $39.1,48.1$, and 66.1). In reality, the level of Indigenous involvement could range from trivial to substantial, as the phrase "to the extent possible" allows authors to decide what they deem to be possible in regard to seeking input from Indigenous Peoples. Furthermore, to my knowledge there are 
no published guidelines on how to document the process of consultation within the recovery documents.

This project aims to determine the general level of involvement of Indigenous Peoples in recovery planning for species at risk in Canada, and to find the geographical and taxonomic areas that require the most improvement in involving Indigenous Peoples in the species at risk recovery process. To do this, I analyzed the content of species at risk recovery documents and developed a scoring system to quantify the level of Indigenous Peoples' involvement evident in the document. I elicited expert opinions to substantiate the scoring system, and I contacted authors of a subsample of documents to confirm levels of involvement. Specifically, my thesis addresses the following questions:

1. What is the average level of involvement of Indigenous Peoples in species at risk recovery processes in Canada?

2. Does the region in which a species is found affect the level of involvement of Indigenous Peoples in that species' recovery process? If so, what region(s) have more evidence of involvement of Indigenous Peoples?

3. Does the taxonomic category of a species affect the level of involvement of Indigenous Peoples present in that species' recovery process? If so, which taxonomic groups have more evidence of involvement of Indigenous Peoples? 
4. Has the level of involvement of Indigenous Peoples changed over time based on the publication dates of recovery documents?

5. Does the agency under which the species' recovery document was written affect the level of involvement of Indigenous Peoples?

I predicted that regions with more historically contentious relationships with Indigenous Peoples due to factors such as large numbers of unsigned treaties and multiple court challenges (e.g. British Columbia), would have lower levels of Indigenous involvement. These strained relationships could be based on many reasons such as treaty status or regional racial bias. In addition, I predicted that there would be more evidence of the involvement of Indigenous Peoples in the recovery documents of species that are considered to be culturally significant. I predicted that more charismatic taxa such as birds and mammals would have higher levels of evidence of Indigenous involvement as a result of these species receiving more general conservation efforts (Bonnet et al., 2002). I also predicted that evidence of the involvement of Indigenous Peoples would be less frequent in aquatic and marine species, as many of these species are economically important and implementing an effective recovery plan may negatively affect income associated with the species (Findlay et al., 2009). As a result, Indigenous involvement could more likely be intentionally overlooked for these species, as it could complicate recovery measures further. By viewing all recovery documents of all species at risk, I was able to analyze the context within each document 
insinuating Indigenous involvement using a scoring system and statistical tests to demonstrate patterns.

\section{Methods:}

Document Context Analysis:

I used the Canadian Species at Risk Act (SARA) public directory website to obtain species at risk recovery documents. I read all recovery strategies and management plans for species with their SARA Schedule 1 status labeled as endangered, threatened, and special concern for indication of involvement of Indigenous Peoples. Recovery strategies and management plans are created at the same point in the species recovery process, depending on if the species' status is endangered or threatened (recovery strategies) or special concern (management plans). I decided that I would not assess action plans because there were relatively few of these documents compared to recovery strategies and management plans, and most of these plans included multiple taxa, complicating comparison among taxa. Plans for multiple taxa presented an issue, as there was often no clarification on which species Indigenous Peoples or organizations were consulted about.

I reviewed each document in its entirety for records of Indigenous involvement, with specific focus on the Preface, Acknowledgements, and Appendices, where nearly all records were found. After I searched each document manually, I used the "find" function to search for key words and phrases that may have suggested 
the involvement of Indigenous Peoples in each document. These words and phrases included: "Aboriginal”, "First Nation", "nation", "Indian”, "band", "Metis", "Indigenous", "Inuit", "tribe”, "tribal”, "council”, "people”, and "community". I reviewed all management plans and recovery strategies published up to December 2017. If both proposed and final documents were available, I reviewed final documents, but when only proposed versions were available, I reviewed them and used them for analysis.

I considered a document to contain evidence of Indigenous involvement when it was clear that the involvement took place at the time of the document's formation. The mere inclusion of what may be seen as Aboriginal traditional knowledge is not considered equivalent to meaningful consultation (Maritime Aboriginal Peoples Council, 2014) and therefore I did not count it as such. I also did not consider the following to be Indigenous involvement: references to species populations being found on Indigenous lands, general statements of cultural significance or use (e.g. plants affected by First Nations fire regimes), future plans for collaboration with Indigenous Peoples, and past recovery efforts put forth by Indigenous Peoples or organizations.

\section{Scoring System Development:}

I developed a scoring system to estimate the level of Indigenous Peoples' involvement in the recovery documents. I used expert elicitation to help construct and refine this scoring system, to ensure it was accurate and defendable. I sent a draft of the scoring system along with initial data sheets to eight professionals 
within the field of conservation biology with experience in Indigenous conservation. All eight persons provided positive feedback regarding the draft scoring system, as well as suggestions for follow-up described below, to examine the precision of the scoring system.

The system categorized the level of Indigenous involvement using a six-point scale in which a score of zero represents no involvement at all and a score of five represents the highest level of collaboration. A score of zero could indicate no detectable effort put towards obtaining Indigenous involvement, or it could represent declined involvement on the part of the Indigenous person or group. I eliminated all clear cases of declined involvement from the data (see below for details).

I considered several situations to represent involvement and consultation with Indigenous Peoples. Many plans included a general statement in the acknowledgements thanking Aboriginal organizations for contributing to the plan. Others were more specific by mentioning the name of the Aboriginal organization, band, or tribal member in the acknowledgements, preface, or a section in some of the documents called the "Record of Consultation". In some cases, Indigenous Peoples were included as members of the recovery team, personally consulted, or served as technical advisors. I scored all of these instances using the criteria for each score level listed in the complete scoring system in Appendix A. 
To examine the precision of the scoring system, I emailed the authors or listed contacts of ten randomly-selected documents from each score category (0-5, for a total of 60 contacts) a short survey asking them to provide their firsthand knowledge on the Indigenous involvement process in a specific document. The questions included:

1. In three sentences or less, please describe the process of consultation with Indigenous Peoples/organizations that you undertook during the formation of your species at risk recovery document.

2. In three sentences or less, please describe the information that you collected from Indigenous Peoples/organizations (even if it may not have been used within the recovery document).

Of the 60 species recovery documents whose authors were contacted with a survey asking about Indigenous involvement, I received seventeen responses to the survey questions. I received five responses in which the authors stated that they had no knowledge of the consultation process that happened during the formation of their document. In addition, two authors responded that they were unwilling/unable to release information regarding Indigenous involvement or were unable to locate the information. I received one response for a document that I originally assigned a score of zero, in which the answers indicated involvement of one Indigenous organization by means of a letter and a meeting, though this was not stated within the document. I received two responses for a species document assigned a score of 1 , meaning the document had a vague mention of 
Indigenous involvement. However, one of the survey responses indicated no Indigenous involvement at all and the other stated that First Nations may have attended presentations. I received five responses for documents assigned a score of two, meaning specific Indigenous organizations/individuals were named, but their exact role was unclear in the document. All of these responses confirmed Indigenous involvement, with two stating that an Indigenous organization or representative attended a meeting and provided information on the species and the other three describing comments received during the document's response period. I received one response for a species document assigned a score of 3, meaning an Indigenous group was listed specifically along with the information they provided. The survey response supported the qualifications of the assigned score. I received no responses for documents assigned a score of four. I received one response for a species document assigned a score of five, indicating the highest level of involvement or coauthorship. The response only mentioned Indigenous interest in species recovery and implementation, although the document lists Indigenous representatives as recovery team members, along with traditional knowledge. Although these results suggest some uncertainty in the scores among individual species, they do not, on balance, suggest directional bias in our scores.

\section{Data Processing:}

The data underwent several steps of elimination, resulting in the most interpretable data set possible (Figure 1). First, I eliminated species whose 
ranges do not overlap with Indigenous lands. The species range maps were provided by Environment and Climate Change Canada (2017) and the "Aboriginal Lands of Canada" map was provided by Natural Resources Canada (2014). I used the Intersect tool in ArcMap 10.3.1 to create a layer showing the overlapping areas of Indigenous lands and species ranges. I imported this intersect layer into R studio (version 0.98 .507 ), to produce a list of the species whose ranges intersect with Indigenous lands. Aquatic and marine species were not included in the species range maps provided by Environment and Climate Change Canada, but were retained in the data to be analyzed. It is possible that even if aquatic and marine species were included in the maps, some species may not overlap with Indigenous lands. However, because we do not have accurate range estimates for these taxonomic groups, and because many of the marine and aquatic species are of interest to Indigenous Peoples, I kept these species in the analysis.

I then removed instances of species for which Indigenous Peoples declined involvement in recovery planning. Declined involvement was often indicated in recovery documents by statements to the effect that letters were sent to Indigenous groups/organizations, but no comments were received, or that Indigenous groups/organizations were invited to participate in the recovery efforts, but they declined. Only $9.8 \%$ of the plans indicated declined involvement. The percentage of declined involvement per region can be found in Table A1. It is possible that some of the remaining documents with zero scores were a result 
of declined involvement, but it was not explicitly stated that the opportunity for involvement was declined.

I included the majority of multi-species plans in the analysis as a single entry, as long as all of the species were in the same taxonomic category. I removed only one multi-species recovery strategy (Multi-species at Risk in Gary Oak Woodlands) from the analysis because it encompassed both plants and arthropods, and it was not clear which taxonomic group was the focus of the involvement with Indigenous Peoples.

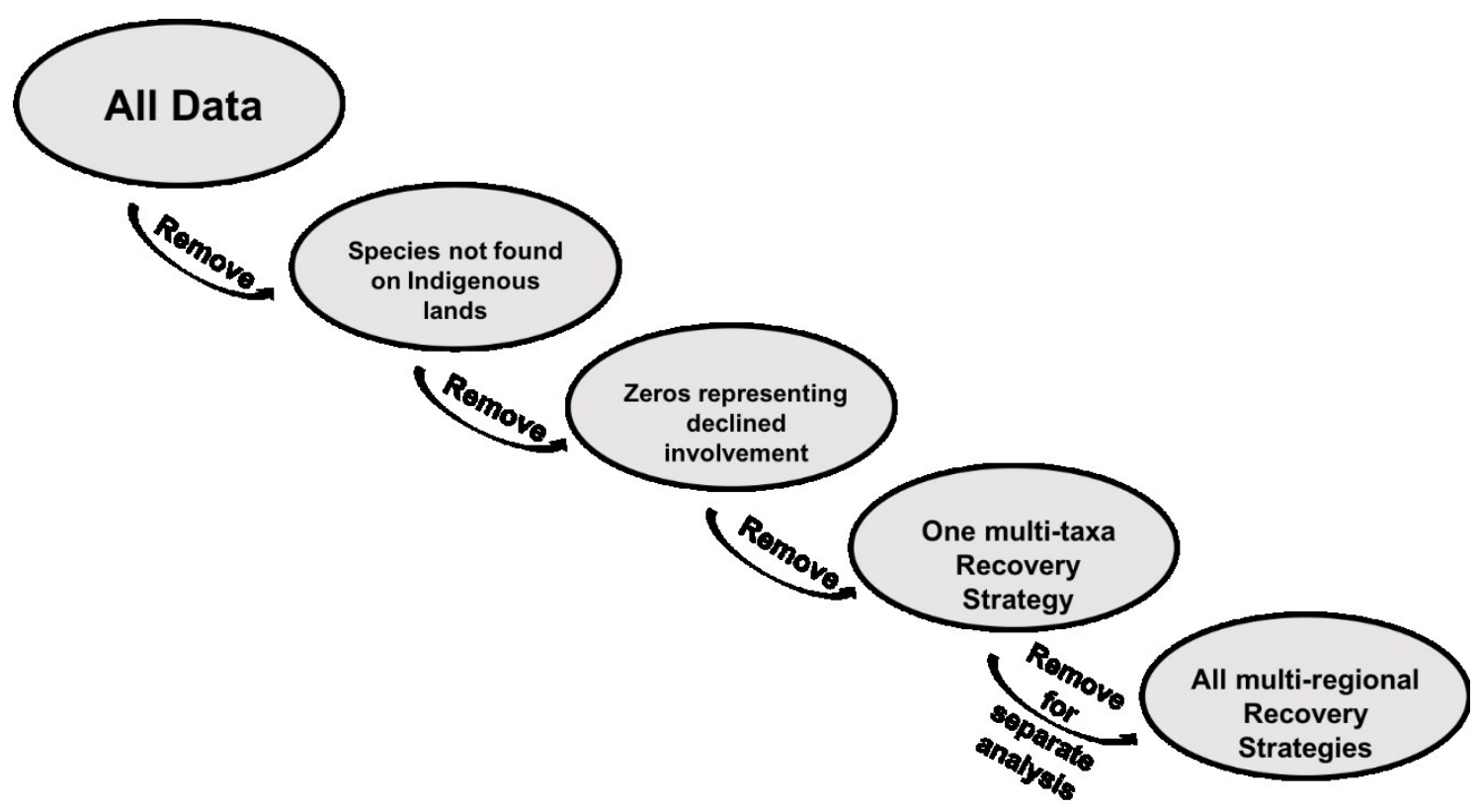

Figure 1. Flow chart representing the steps taken to clean data for final analysis.

Geographic and Taxonomic categories:

I sorted species by the following taxonomic groups (SARA, 2018): mammals, birds, reptiles, amphibians, fish, arthropods, molluscs, vascular plants, mosses, 
and lichens. I also categorized them according to the locations of their ranges in the following regions: Ontario, Quebec, Western Canada (British Columbia and the Pacific Ocean), Central Canada (Saskatchewan, Alberta, and Manitoba), East Coast/Maritimes (Nova Scotia, New Brunswick, Prince Edward Island, Newfoundland and Labrador, and the Atlantic Ocean), and Northern/Arctic Canada (Yukon, Nunavut, Northwest Territories, and the Arctic Ocean).

I included species whose range included more than one geographical region in each individual occupied region. If there was an Indigenous group or groups involved in the species' document, I investigated the location of the groups to determine if the score would remain the same for each region within the species range, or only be applied to the region in which the involved Indigenous group is located. Therefore, some species documents could be assigned different scores in each of their different regions. Because of this, I kept the data with some species being listed several times (but not necessarily with the same score), and conducted an additional analysis eliminating all species that appeared in multiple regions. The results of this analysis are in Appendix B.

\section{Statistical Analysis:}

Given that the data were not normally distributed, and in particular had a large number of zero values with a defined maximum value, I used permutation based statistical tests (Anderson, 2001). To test for significant differences in score based on document type (recovery strategy or management plan), I used a pairwise permutation test. I then used a permutation based ANOVA to determine 
if there was a significant interaction between the type of document and region, followed by the type of document and taxonomic group. I found no significant interaction between the type of document and region or taxonomic group.

To test for an interaction between region and taxonomic groups, I used a permutation based ANOVA. As the interaction term was not significant $(P=0.38)$, I ran separate permutation based ANOVAs for regional groups and then for taxonomic categories. Then, to test for the differences among the categories for each of these variables, I ran pairwise permutation tests.

To test for significant differences in scores among responsible agencies, I first determined the agency responsible for each plan [Fisheries and Oceans Canada (DFO), Environment and Climate Change Canada, or Parks Canada]. I then used a permutation based ANOVA followed by a pairwise permutation test to test for significant differences in scores between each agency. Additionally, I used a permutation based ANOVA to test for a significant interaction between agencies and regions. As this interaction term was significant (see Results below), I used a pairwise permutation test to test for significant differences in scores between each agency and each regional category. Results of this analysis are presented in Appendix B. Because many taxonomic groups were not represented by certain agencies, I did not test for significant differences between agency and taxonomic scores, and the agency tests were not included in the main model testing for differences among taxonomic groups. 
To determine whether the level of involvement of Indigenous Peoples has changed over time based on the publication dates of recovery documents, I plotted the mean score for each year that recovery documents were published, and ran an ordinary least squares regression.

Given that some species were found in multiple regions, and there was thus some non-independence when counting these species for each region (despite the fact that scores could vary between regions), I conducted an additional analysis after removing all multi-regional plans. This decreased the number of documents from 477 to 257 (Figure A1). I ran a permutation based ANOVA on each new set of data to find overall significant difference between categories. I then ran a pairwise permutation test to find significant differences between regions followed by the same tests for taxonomic category. All tests were conducted using R (version 3.3.4). I corrected the P-values for pairwise permutation tests for multiple comparisons using the Holm method (Holm, 1979).

\section{Results:}

General patterns among all species:

I found that $52 \%$ of all documents received a score of zero, meaning over half of all recovery documents included no detectable involvement of Indigenous Peoples. The central, Quebec, and western regions showed the highest percentages of zeros: over $50 \%$ of recovery documents for each of these regions had a score of zero (Table A2). Amphibians, arthropods, lichens, and mosses showed the highest percentages of zeros (over $60 \%$ ), whereas birds, molluscs 
and plants had intermediate percentages, and fish, mammals, and reptiles had less than $40 \%$ zeros (Table A3).

Examples of no evidence of Indigenous involvement in recovery planning include species such as the prairie subspecies of the loggerhead shrike (Lanius ludovicianus excubitorides), as well as many bat species such as the pallid bat (Antrozous pallidus). These recovery documents contained no mention of Indigenous Peoples. However, some documents receiving a score of zero did mention Indigenous Peoples, but did not represent meaningful consultation/involvement. This was the case for both the snapping turtle (Chelydra serpentinea) and wood turtle (Glyptemys insculpta), which contained small paragraphs dedicated to describing the general cultural importance of all turtles, but no documentation of actual Indigenous involvement.

The next most common score was a score of one which was assigned to $22 \%$ of all the recovery documents. This score represents a general statement of Indigenous involvement with no specifics describing information contributed and no Indigenous group/individual name listed. Examples of species whose recovery documents were assigned this score include several turtle species, along with birds including the Canada warbler (Cardellina canadensis), and eastern whippoor-whil (Caprimulgus vociferous). About $9 \%$ of recovery documents were assigned a middle score of three. One example is the southern mountain population of the woodland caribou (Rangifer tarandus caribou). Only $6.5 \%$ of all recovery documents were assigned the highest score of five, representing 
evidence of meaningful involvement and co-management within the document. This was usually represented by naming Indigenous individuals/organizations as co-authors, editors, or major contributors in some way (see appendix A for details). Some examples of species with this score are the culturally significant species northern abalone (Haliotis kamtschatkana) and the Inner Bay of Fundy population of Atlantic salmon (Salmo salar).

Regional and Taxonomic variables:

There was a significant difference in mean score between recovery strategies (mean: $1.23 ; \pm 0.087$ standard error $(\mathrm{SE}))$ and management plans $(0.80 \pm 0.11$; $\mathrm{P}=0.0039$ ). However, in permutation-based ANOVAs examining differences in mean scores, there was no significant interaction between the type of document and (1) region $(P=0.18)$ or (2) taxonomic group $(P=0.73)$ (Table A4 \& A5).

The interaction term between region and taxonomic group was not significant $(P=0.38 ;$ Table A6). However, there were significant differences among regions $\left(P=2.2 \times 10^{-16}\right)$ and among taxonomic groups $\left(P=2.2 \times 10^{-16}\right)$. Central Canada and Quebec had the lowest mean scores of $0.39( \pm 0.11 \mathrm{SE})$, and $0.70( \pm 0.13$ SE), respectively, while other regions had significantly higher mean scores (Figure 2 \& Table A7). Mosses, arthropods, and amphibians had the lowest mean scores of the taxonomic categories. All recovery documents for mosses were assigned a score of zero for no involvement, while arthropods had a mean score of $0.44( \pm 0.16 \mathrm{SE})$, and amphibians had a mean score of 0.80 ( $\pm 0.38 \mathrm{SE}$; 
Figure $3 \&$ Table A8). Mammals $(1.94 \pm 0.27)$ and fish $(1.95 \pm 0.26)$ had the highest mean scores.

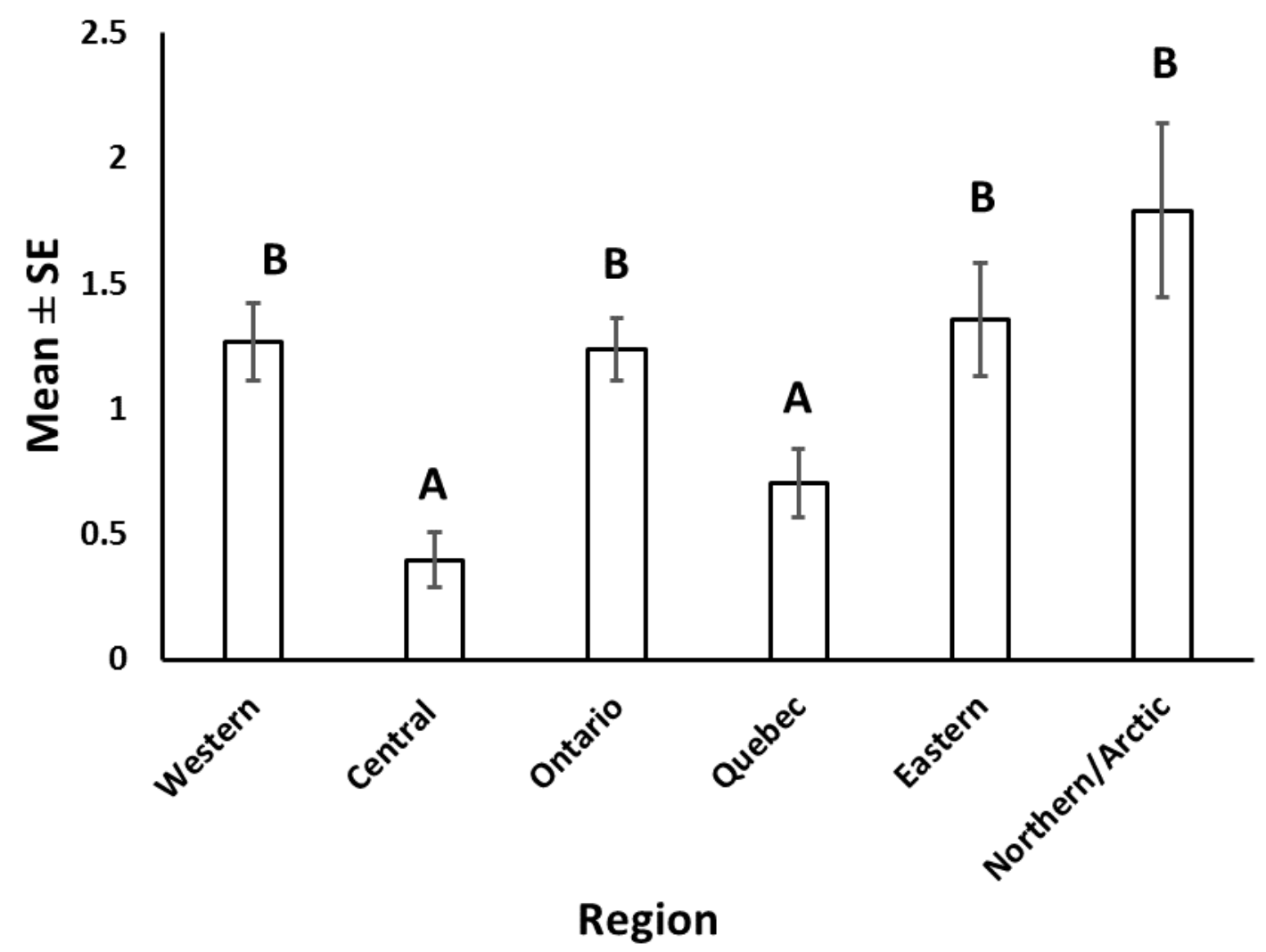

Figure 2. Mean score for evidence of Indigenous involvement in recovery strategies and management plans by region ( \pm standard error $(\mathrm{SE})$ ). The letters above each bar represent groupings based on significant differences in pairwise permutation tests. Western region (Pacific Ocean and British Columbia: $n=131$ ), central region (Alberta, Saskatchewan and Manitoba: $n=68)$, Ontario $(n=134)$, Quebec $(n=64)$, eastern region (Nova Scotia, New Brunswick, Prince Edward Island, Newfoundland and Labrador, and the Atlantic Ocean: $n=56$ ), northern/arctic region (Yukon, Nunavut, Northwest Territories, and the Arctic Ocean: $n=24)$. 


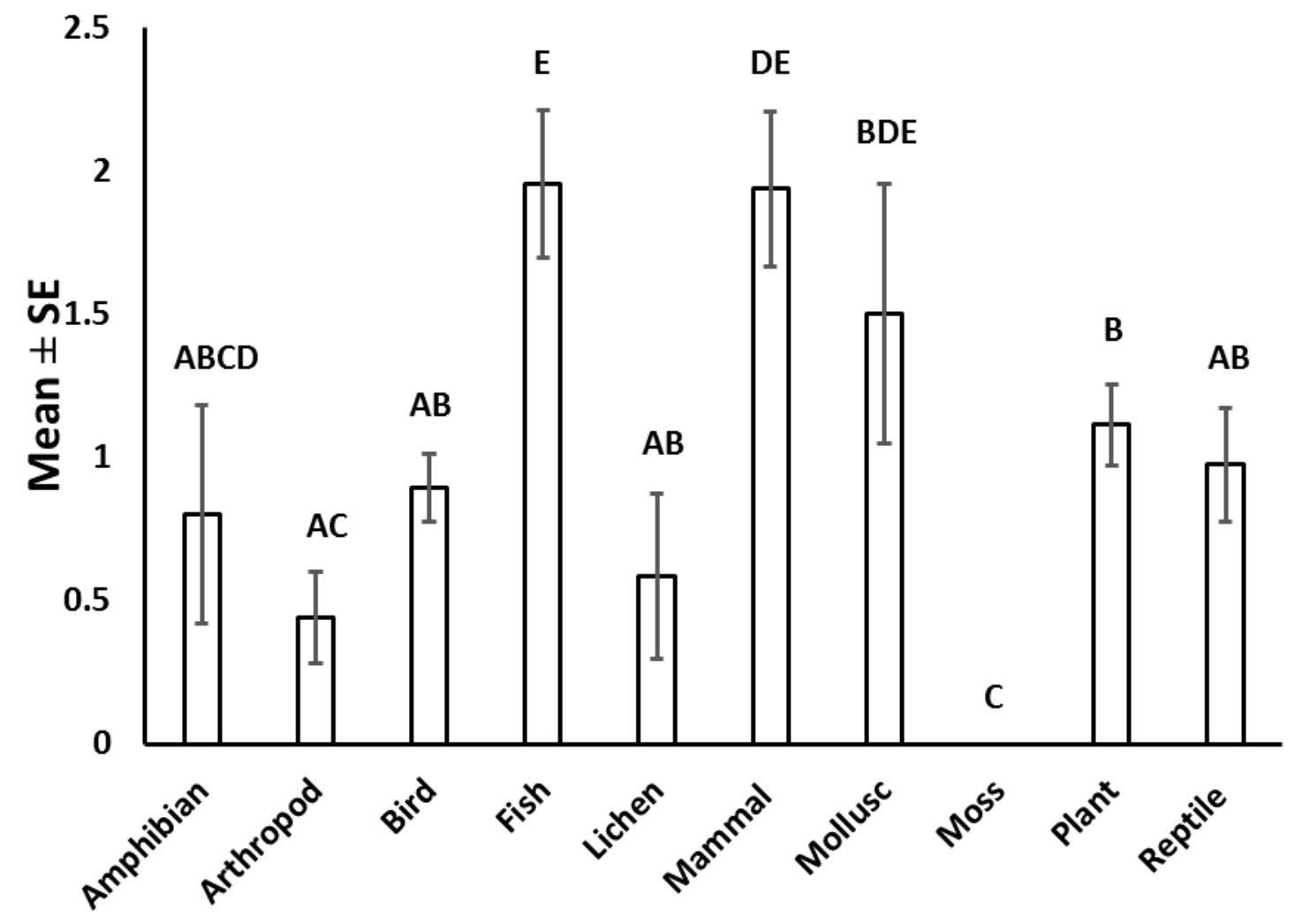

Taxon

Figure 3. Mean score for evidence of Indigenous involvement in recovery strategies and management plans by taxonomic category ( \pm standard error (SE)). The letters above each bar represent groupings based on significant differences in pairwise permutation tests. Amphibians $(n=20)$, arthropods $(n=34)$, birds $(n=$ $123)$, fish $(n=44)$, lichens $(n=12)$, mammals $(n=48)$, molluscs $(n=14)$, mosses $(n=20)$, plants $(n=123)$, reptiles $(n=39)$.

Differences among management agencies:

Documents for species for which Fisheries and Oceans Canada (DFO) was the lead agency had the highest mean score at $2.18( \pm 0.20 \mathrm{SE})$, while those from Parks Canada had a mean score of $1.55( \pm 0.28 \mathrm{SE})$ and those from Environment and Climate Change Canada had the lowest mean score at $0.81( \pm$ 
0.067 SE). Pairwise permutation tests showed significant differences between scores of Environment and Climate Change Canada and DFO $\left(P=4.51 \times 10^{-13}\right)$, and Environment and Climate Change Canada and Parks Canada $\left(P=5.99 \times 10^{-}\right.$

$\left.{ }^{4}\right)$. The mean score for DFO was marginally significantly different from that of Parks Canada $(P=0.062)$ (Figure A2 \& Table A9).

The additional permutation based ANOVA to determine the relationships between agency and region resulted in a significant interaction term $\left(P=2.2 \times 10^{-}\right.$ $\left.{ }^{16}\right)$ (Table A10). Full results for the pairwise permutation test can be found in Appendix B (Table A11).

\section{Trends Across Time}

The year that each document was published was not correlated with the score of Indigenous involvement $(r=0.23 ; P=0.47$; Figure A3).

Additional Analysis - Removing Multi-Regional Species:

In the additional analysis removing multi-regional species, results were similar to the main data set. There was no significant interaction between the taxonomic and regional categories $(P=0.19)$ (Table A12). Central Canada and Quebec remained the regions with the lowest scores for evidence of Indigenous involvement, and western Canada was no longer significantly different from these regions. The eastern and northern regions retained the highest mean scores (Figure A4 \& Table A13). The mean score trends of the taxonomic analysis after removing species that were found in more than one region are comparable to the 
original analysis; however most taxonomic categories were not significantly different (Figure A5 \& Table A14).

\section{Discussion:}

Over half $(52 \%)$ of all the documents analyzed were assigned a score of zero, indicating very little involvement of Indigenous Peoples in the Canadian species at risk recovery process. These results are troubling, especially given the clear instructions within SARA to consult with Indigenous Peoples and incorporate ATK "to the extent possible", and the specific requirement to consult with Indigenous Peoples who may be affected by species at risk recovery. It is difficult to believe that Indigenous Peoples have no vested interest in the recovery of over half of the species at risk in Canada.

There are numerous possible reasons for no Indigenous involvement. Many of the documents stated that letters were sent to Indigenous groups/organizations, but letters could have been sent to an office or person not equipped for making decisions of this nature (Joseph, 2015). Using only a letter as the method of contact is especially problematic for Indigenous groups with small administrations that may be overworked and unable to respond in the required time frame.

The adverse relationships between Indigenous Peoples and federal/provincial governments across Canada may also be a reason for little Indigenous involvement in the species recovery process. Ayers (2005) explained that some Indigenous Peoples are hesitant to become involved with development of marine protected areas (MPAs) because they feel it may risk their position in treaty 
processes. Becoming involved in the recovery process of species at risk may evoke fear in the same way. In addition, the consultation process can be confusing to some Indigenous peoples (Bains \& Ishkanian, 2016). Some Indigenous organizations have even published on their websites guides to clarify for their membership the recovery process and explain how Indigenous Peoples can become involved (e.g. Assembly of First Nations, 2009). A history of insufficient consultations with Indigenous Peoples may also be a reason for either no involvement or declined involvement. This is demonstrated by a study by LeRoy et al., (2003), which found that concerns about the establishment of an MPA were partially caused by inadequate consultations in the past. Clearer guidelines on Indigenous involvement within SARA and reassurance to Indigenous Peoples of the value of Indigenous knowledge and perspectives may encourage Indigenous Peoples to become more involved in the species at risk recovery process.

Quebec and Central Canada have the lowest levels of Indigenous involvement as well as the highest percentages of zero scores out of all the regions, with the Eastern, Northern, and Western regions, as well as Ontario, having significantly higher scores (Figure 2). I expected that recovery documents for species found in Western Canada (which includes B.C. and the Pacific Ocean) would have lower scores because of the large number of unsigned treaties in B.C., and therefore ill-defined boundaries of Indigenous land and its overlap with species at risk habitats. My results do not support this hypothesis. Although the western region 
does have a high percentage of zero scores, the plans that do show evidence of Indigenous involvement have relatively high scores.

The significant interaction between responsible agency and region may be a partial cause for low scores in specific regions. However, within the single agency Environment and Climate Change Canada, central Canada does have a significantly lower mean score than the other regions, suggesting that the cause of low scores for Indigenous involvement in central Canada is not entirely a result of the high number of species in that region that are under the responsibility of Environment and Climate Change Canada.

I speculate that one cause may be that there is possible greater racial bias against Indigenous Peoples in the regions of central Canada and Quebec, however I acknowledge that the definite cause is unclear. The Urban Aboriginal Peoples Study (2011) surveyed Indigenous and non-Indigenous Peoples in 11 cities across Canada, to measure the attitudes towards Aboriginal Peoples living in urban areas. When Aboriginal Peoples were asked about the way they felt they were perceived by non-aboriginal peoples, the results were mostly negative across all 11 cities, but cities in central Canada and Quebec had the lowest levels of positive perceptions with Winnipeg having only a $9 \%$ positive response, Edmonton having 10\%, Regina having 11\%, and Montreal having just a $12 \%$ positive response (Urban Aboriginal Peoples Study, 2011). Though these particular results are based on the way Aboriginal Peoples feel that they are seen by non-aboriginal peoples (presumably based on their treatment), they do 
suggest the possibility of greater racial bias in these areas. This racial bias could be a cause of reluctance from both the government and Indigenous Peoples to cooperate with each other, especially if the Indigenous groups in question feel that they themselves are not respected and valued by the people seeking their input.

Among taxonomic groups, fish received the highest average score for Indigenous involvement, with mammals (including marine mammals) and molluscs being the second and third highest average scores (Figure 3). This did not support my hypothesis that aquatic and marine species would have lower levels of Indigenous involvement. Many marine and aquatic species are economically important and are less likely to be listed under SARA (Findlay et al., 2009; Creighton \& Bennett, in review) and prioritized for management (Mooers et al., 2010). However, many of the Atlantic marine species recovery documents included involvement from the Maritime Aboriginal Peoples Council, increasing the average scores. Species such as the Atlantic whitefish (Coregonus huntsman) and Inner Bay of Fundy populations of Atlantic salmon include members from the Maritime Aboriginal Peoples Council as contributors and members of recovery teams. The Council was also involved with the recovery of several terrestrial species in the eastern region.

Mammals had the second highest average scores, while mosses, lichens, and arthropods had the lowest scores, supporting my hypothesis of greater involvement of Indigenous species in recovery documents for more charismatic 
taxa. This trend reflects a consistent bias, with greater attention in general being paid to charismatic taxa, and most conservation research still being focused on vertebrates (mainly mammals and birds; Di Marco et al., 2017; Donaldson et al., 2016; Martín-López et al., 2007).

The lack of correlation between document score and year published suggests that the amount of Indigenous involvement has not changed over time, despite updated guidelines for Indigenous consultation in Canada along with a heightened Indigenous social movement (Government of Canada, 2011). However, I found that the agency responsible for recovery planning was strongly related to document score, with DFO receiving the highest average score of all of the agencies, and Environment and Climate Change Canada receiving a significantly lower average score than DFO or Parks Canada. This is an interesting contrast to findings by Findlay et al. (2009) that species under the responsibility of DFO were less likely to be listed as at risk in the first place, suggesting that DFO may have been failing in its duty to protect species at risk under its jurisdiction. However, Findlay et al. (2009) did state that many DFO species that were not listed were subjected to extended consultation. While this may have been seen as a delay tactic in listing species, it could also be seen as DFO performing their due diligence in meaningful consultation, which consequently requires more time.

SARA's guidelines for consultation with Indigenous Peoples are ambiguous, and allow for authors to interpret for themselves what represents meaningful 
consultation on a case by case basis. Because of this, it is possible that authors were unaware of what to consider worthy consultation to include in a recovery document. Because SARA only requires that Aboriginal organizations be involved in recovery documents "to the extent possible" and only requires involvement with the organizations that the minister believes will be affected by a plan (SARA, 2002), it gives almost free rein to authors to decide on what level of Indigenous involvement to include. As a result, some authors may not take the duty to consult as a serious obligation (e.g. they simply send a letter that goes unanswered), but are still able to use the phrase "to the extent possible" to suggest that Indigenous involvement was sufficiently pursued. Furthermore, if consultation is attempted in a way that is not culturally accommodating and respectful, Indigenous Peoples may elect to not respond. In this case, more specific guidelines are not as important as cultural accommodation and a heightened value of traditional knowledge.

The lack of specific requirements for Indigenous involvement in the recovery process also leaves room for miscommunication and disregard for certain Indigenous groups over others that are known to be more likely to cooperate. There can also be a disconnect between Indigenous governments and their general members (e.g. issues between Indian Act chiefs and grassroots movement Idle No More (Warrior Publications, 2013)). This could create a risk that group members who have different perspectives or knowledge on a species at risk may not be consulted by their tribal/band council. In some cases, 
grassroots perspectives may even be deliberately ignored by fellow Indigenous people holding more power (e.g. CBC News, 2014).

\section{Caveats}

It is important to note that my study only examines whether there is evidence that Indigenous groups or individuals were involved in the development of the recovery strategies and management plans. It is possible that Indigenous Peoples were involved in recovery efforts at the time of plan development, and therefore may have influenced the writing of a document, but that this is not evident in the document. In some cases, Indigenous Peoples may have been involved in this way or in a more direct way, but authors of the document may have been uncertain on what to consider cooperation/consultation for the document. In addition, I considered the statement "no comments were received" to represent declined involvement from Indigenous Peoples. It is possible that this did not represent declined involvement in certain plans, however, there is no way to know the actual reason behind the lack of responses from Indigenous Peoples for each document.

I considered co-developers and editors of plans to represent the highest level of involvement with a score of 5 because it is often the case that these roles play a similar role to co-authorship. It is possible that the roles of authors or editors represent different levels of involvement. However, these instances were represented by a score of 5 for the purposes of this study, since there is no clear description of the duties of these positions in the documents. 
As noted above, surveys of authors of recovery documents suggested some inconsistencies between the scores obtained via document analysis and the actual level of Indigenous involvement as described by the authors. However, results of this survey generally agreed with the assigned scores, while suggesting that some scores may have been underestimated, while others may have been overestimated. On balance, I am confident that my scores reflect general patterns of Indigenous involvement among regions and taxonomic groups.

Conclusions and recommendations:

To improve Indigenous involvement in the species at risk recovery process, I suggest clearer and more precise guidelines for the inclusion of Indigenous knowledge and perspectives into recovery documents. This would allow less room for author interpretation, and help to equalize effort in the pursuit of Indigenous cooperation. I also suggest transparency in the way Indigenous involvement is documented. This would provide proper credit and acknowledgement to the Indigenous Peoples or organizations who have provided information, better highlighting the value of Indigenous knowledge. In addition, it would make the public aware of the extent of Indigenous involvement behind the recovery process. It is possible that greater scrutiny allowed by precise documentation would force agencies to a higher standard of Indigenous involvement as well. This increased transparency could perhaps include the elimination of the ambiguous phrase "to the extent possible" from the 
Act itself, as well as clarification about certain roles such as personal communications and technical advisors. Specifying the levels of Indigenous involvement that actually took place (i.e. groups contacted, if individuals were actually spoken to, what types of information/perspectives were received and included in the recovery plan) would ensure there is more meaning behind the phrases used to describe Indigenous involvement.

Although my survey results mostly support my scoring system and do not suggest a systematic bias toward over- or under-representation of Indigenous Peoples' involvement in recovery documents, discrepancies in the responses show that not all information and appropriate acknowledgement is being provided within the documents. This shows that Indigenous involvement is not always properly documented, and, conversely, may sometimes be exaggerated. Responses from my author survey also showed that for some species, Environment and Climate Change Canada was unable to find some of the information on Indigenous involvement. Therefore, I suggest better documentation of Indigenous involvement not just within documents, but also within the government records.

Further research could be conducted to investigate the reasons behind the lack of or low level of Indigenous involvement in the central region and Quebec. For example, a survey or a series of interviews with Indigenous groups and individuals in these areas to gather first-hand information on their involvement in conservation and the species at risk recovery process. This information would 
lead to more specific solutions on how to increase co-management between government agencies and Indigenous groups within these areas. Solutions specific to these areas could also be applied to co-management with Indigenous Peoples in conservation in general.

This study provided insight into the levels of Indigenous involvement in species at risk recovery documents throughout Canada. The low levels of involvement in central Canada (Alberta, Manitoba, and Saskatchewan) and Quebec show where the most work is needed in these areas in particular. The scores for Indigenous involvement are also consistent with the idea that less iconic taxa (mosses, lichens, and arthropods) are not only neglected in conservation research and prioritization, but also in eliciting Indigenous perspectives. Because the level of Indigenous involvement has not increased over time, it is clear that new specific standards need to be implemented for the process of Indigenous involvement in species at risk recovery. The significantly lower level of Indigenous involvement for species under Environment and Climate Change Canada compared to DFO and Parks Canada demonstrates that the responsible agency for the species at risk does have an effect on the level of Indigenous Involvement as well. Pinpointing the areas where improvement is needed is especially important, as respect for the rights of Indigenous Peoples and the value of Indigenous knowledge is increasingly recognized. Although this study is focused on Canadian species at risk, co-management of natural resources between 
governments and Indigenous peoples is essential for effective ecological management worldwide. 


\section{CHAPTER THREE}

GENERAL SUMMARY 
Co-management of natural resources and land between governments and Indigenous peoples provides many benefits to both parties. If considered valid and legitimate, Indigenous knowledge and perspectives can bring information to the table that would otherwise be unknown. Through trial and error over thousands of years, Indigenous Peoples have been able to determine what constitutes successful and unsuccessful management strategies to preserve the resources they have relied on to survive (Gadgil et al., 1993). This information is often trivialized by non-Indigenous Peoples and seen as simple stories or anecdotal events (Beckford et al., 2010), but it is much more than that. Information such as trappings, sightings, insight into species behavior, and habitat requirements can all be obtained from Indigenous knowledge. Similar to adaptive management, Indigenous knowledge has been collected with an uncertain future in mind, and with a goal of ecosystem resilience (Berkes et al., 2000).

Successful co-management of natural resources and land between governments and Indigenous Peoples is possible, and can be seen in several examples across Canada and the world. Failing et al. (2013) describes one such situation in Western Canada, where structured decision making was used to involve the St'at'imc Nation in the restoration of a hydrological regime. The framework they used allowed for all stakeholders and Indigenous people to be educated on the issue at hand, including alternative options which enabled Indigenous people to share educated perspectives as valued contributors (Failing et al., 2013). This 
example could be used as a case study to help achieve meaningful Indigenous involvement, as all parties were valued and both scientific and value-based knowledge were incorporated into restoration plans.

Variations of the label "original conservationists" have been placed upon Indigenous Peoples, becoming a source of debate (Redford, 1991; Raymond, 2007). However, Indigenous People have been conserving natural resources (sometimes unknowingly) for centuries. First Nations on the Northwest Coast have demonstrated this with their ancient clam gardens that allowed them to thrive on this food source for 5000 years. Although these clam gardens had not been tended in decades, they were still found by a scientific study to be productive habitats for clams (Groesbeck et al., 2014). In addition to providing evidence of the adequacy of Indigenous knowledge and conservation practices, this example also shows that oftentimes a layer of western science needs to be placed over Indigenous knowledge in order for it to be seen as accurate. Consequently, if Indigenous knowledge were to be considered legitimate without implementing the scientific method on top of it, time, money, and other resources would be spared.

Despite these adverse attitudes towards Indigenous knowledge, many scientists are starting to realize its benefit to conservation science. Ecological management is beginning to be seen as something that requires diverse perspectives and decision makers in order to be most effective (Carpenter, 2012). Indigenous knowledge and perspectives add a different element to conservation decisions 
and processes, not just providing specific pieces of information, but also a valuebased outlook that differs from that of western science.

In my research I aimed to pinpoint the areas (geographically, taxonomically, and by responsible agency) that have the least amount of Indigenous involvement in their species at risk recovery processes. Finding the areas that need the most improvement provides insight into the reasons why involvement is lacking, and allows for more specific solutions. I tested my hypotheses by first reading through all recovery documents (Recovery Strategies and Management Plans) for Canadian species at risk. I then formulated a scoring system backed by expert elicitation, to quantify the evidence of Indigenous involvement within each document. I calculated average scores by region, taxonomic category, responsible agency, and year published.

I found that $52 \%$ of all recovery strategies and management plans contained no involvement of Indigenous Peoples. Specifically, central Canada (Alberta, Saskatchewan and Manitoba) along with Quebec had the lowest levels of Indigenous involvement for their species recovery documents. In addition, mosses, lichens, and arthropods had the lowest levels of Indigenous involvement among the taxonomic groups, while more charismatic and culturally significant groups had the highest levels. Environment and Climate Change Canada had the lowest average score compared to the other responsible agencies with Parks Canada in the middle and DFO with the highest mean score. There was no 
correlation between a document's year published and its score of Indigenous involvement.

There are numerous possibilities as to why these results were found. I speculate that one of the main causes of such low levels of Indigenous involvement is SARA's non-specific guidelines on how to carry out the consultation process for species at risk recovery. It is stated that, "to the extent possible" the plans must be prepared in cooperation with every Aboriginal organization that could be affected by it (SARA, 2002). This ambiguous phrase is often seen within the documents themselves indicating Indigenous involvement, enhancing the amount of uncertainty towards the level of cooperation and consultation that actually took place. This uncertainty also applies to what actually represents meaningful Indigenous involvement. In a small percentage of all the documents analyzed, the only indication of "consultation" was a letter sent to one or several Indigenous groups. This does not represent meaningful consultation to the extent possible. However, because of the vagueness that accompanies the guidelines for Indigenous involvement in the recovery process, this small amount of effort is obviously seen by some as fulfilling the duty to consult. In addition, many recovery documents state that they have goals/plans to involve Indigenous Peoples in the implementation of recovery actions, but this does not prove collaboration in the actual creation of the plan. Therefore, Indigenous Peoples may have played no part in the decision making process. 
Though it is true that every case of a species at risk and its relationship with Indigenous Peoples differs, establishing specific guidelines for the process of facilitating Indigenous involvement would ensure a more thorough and constant effort to involve each Indigenous group. With increased specificity in the guidelines, however, accommodation for different cultures within the Indigenous community must also be considered. Requests for involvement may be lost in translation if the species at hand is referred to as something else in a traditional language, if traditional knowledge on the species has been lost (Ens et al., 2016), or because of lack of culturally accommodating communication (Lewis \& Sheppard, 2006). I suggest that Indigenous Peoples themselves be fundamentally involved with the writing of these transparent and culturally accommodating new guidelines.

Species known to be essential to the integrity of a culture are more likely to gain support from that culture for their conservation (Garibaldi \& Turner, 2004). My results show that many of the species known as culturally significant are the ones with the most adequate Indigenous involvement. This could also be the result of SARA's requirement to involve only the Indigenous organizations that the Minister believes may be affected by the species recovery (SARA, 2002). However, unless Indigenous Peoples are initially consulted, it may be unknown if a species has cultural significance (Garibaldi \& Turner, 2004). And simply stating that a species has cultural significance (e.g. in the case for the snapping turtle and wood turtle), does not constitute consultation or involvement in planning. 
It is clear that there is much work that needs to be done to improve the process of involving Indigenous Peoples in conservation efforts. Although identifying the areas that need the most improvement can lead to more specific solutions, the most essential step towards adequate Indigenous involvement is to stop undervaluing Indigenous knowledge in science. This, in addition to more specific guidelines for involving Indigenous Peoples in species at risk recovery processes, can lead to more effective conservation practices through the synergistic combination of western and Indigenous knowledge. 


\section{References:}

Alcorn, J. B. 1993. "Indigenous Peoples and Conservation." Society for Conservation Biology 7 (2): 424-26.

Anderson, M. J. 2001. "Permutation tests for univariate or multivariate analysis of variance and regression." Canadian Journal of Fisheries and Aquatic Sciences 58: 626-639.

Assembly of First Nations. 2009. "Assembly of First Nation Species at Risk Act Survival Guide." http://www.afn.ca/uploads/files/env/sara-guide.pdf

Ayers, C. A. 2005. "Marine Conservation from a First Nations' Perspective : A Case Study of the Principles of the Hul' Qumi' Num of Vancouver Island, British Columbia."

Bains, R., and K. Ishkanian. 2016. "The Duty to Consult with Aboriginal Peoples: A Patchwork of Canadian Policies." The Fraser Institute.

Beckford, C., C. Jacobs, N. Williams, and R. Nahdee. 2010. "Aboriginal Environmental Wisdom, Stewardship, and Sustainability: Lessons from the Walpole Island First Nations, Ontario, Canada." Journal of Environmental Education 41 (4): 239-48.

Berkes, F., J. Colding, and C. Folke. 2000. "Rediscovery of Traditional Ecological Knowledge as Adaptive Management." Ecological Applications 10 (5): 125162.

Bonnet, X., R. Shine, and O. Lourdais. 2002. "Taxonomic Chauvinism." Trends in Ecology and Evolution 17 (1): 1-3.

Buchanan, N. 2016. "Which Fish? Knowledge, Articulation, and Legitimization in Claims about Endangered and Culturally Significant Animals." Science, Technology, \& Human Values 42 (3): 520-42.

Carpenter, S. R. 2012. "Ecological Futures : Building an Ecology of the Long Now." Ecology 83 (8): 2069-83.

Castro, A. P., and E. Nielsen. 2001. "Indigenous People and Co-Management: Implications for Conflict Management." Environmental Science and Policy 4: 229-39.

CBC News. "AFN Called 'elitist,' out of Touch with Grassroots First Nations People | CBC News." December 10, 2014. Accessed April 02, 2018. 
http://www.cbc.ca/news/canada/manitoba/afn-called-elitist-out-of-touch-withgrassroots-first-nations-people-1.2866486.

Coates, K. "Liberals Making Gradual but Real Progress on Indigenous Issues: Ken Coates for Inside Policy." MLI. February 21, 2017. Accessed February 21, 2018. https://www.macdonaldlaurier.ca/liberals-making-gradual-but-realprogress-on-indigenous-issues-ken-coates-for-inside-policy/.

Colchester, M. 2004. "Conservation Policy and Indigenous Peoples." Environmental Science and Policy 7 (3): 145-53.

Creighton, M. J. A., and J. R. Bennett. Taxonomic biases from listing to management for Canadian species at risk of extinction. In review.

Department of Justice, Canada. 2018. "Principles Respecting the Government of Canada's Relationship with Indigenous Peoples." http://www.justice.gc.ca/eng/csj-sjc/principles-principes.html.

Di Marco, M., S. Chapman, G. Althor, S. Kearney, C. Besancon, N. Butt, J. M. Maina, et al. 2017. "Changing Trends and Persisting Biases in Three Decades of Conservation Science." Global Ecology and Conservation 10: $32-42$.

Donaldson, M. R., N. J. Burnett, D. C. Braun, C. D. Suski, and S. G. Hinch. 2016. "Taxonomic Bias and International Biodiversity Conservation Research." Facets 1: 105-13.

Ens, E., M. L. Scott, Y. M. Rangers, C. Moritz, and R. Pirzl. 2016. "Putting Indigenous Conservation Policy into Practice Delivers Biodiversity and Cultural Benefits." Biodiversity and Conservation 25 (14): 2889-2906.

Environment and Climate Change Canada. (2017). Unpublished data on Species at Risk ranges in Canada [Data file]. Retrieved from http://donnees.ec.gc.ca/data/species/protectrestore/range-map-extentsspecies-at-risk-canada/

Failing, L., R. Gregory, and P. Higgins. 2013. "Science, Uncertainty, and Values in Ecological Restoration: A Case Study in Structured Decision-Making and Adaptive Management." Restoration Ecology 21 (4): 422-30.

Findlay, C. S., S. Elgie, B. Giles, and L. Burr. 2009. "Species Listing under Canada's Species at Risk Act." Conservation Biology 23 (6): 1609-17. 
Gadgil, M., F. Berkes, and C. Folke. 1993. "Indigenous Knowledge for Biodiversity Conservation." Ambio 22 (2): 151-56.

Garibaldi, A., and N. Turner. 2004. "Cultural Keystone Species : Implications for Ecological Conservation and Restoration." Ecology and Society 9 (3).

Government of Canada. 2002. "Species at Risk Act." Minister of Justice.

Government of Canada. 2011. "Aboriginal Consultation and Accommodation: Updated Guidelines for Federal Officials to Fulfill the Duty to Consult."

Groesbeck, A. S., K. Rowell, D. Lepofsky, and A. K. Salomon. 2014. "Ancient Clam Gardens Increased Shellfish Production: Adaptive Strategies from the Past Can Inform Food Security Today." PLoS ONE 9 (3).

Haida Nation v. British Columbia (Minister of Forests). 3 S.C.R. 511, 2004 SCC 73, 2004.

Holm, S. 1979. "A Simple Sequentially Rejective Multiple Test Procedure." Scandanavian Journal of Statistics 6: 65-70.

Horstman, M., and G. Wightman. 2001. "Karparti Ecology: Recognition of Aboriginal Ecological Knowledge and Its Application to Management in North-Western Australia." Ecological Management and Restoration 2 (2): 99-109.

Joseph, B. "12 Common Mistakes in First Nation Consultation." Indigenous Corporate Training Inc. July 02, 2015. Accessed March 23, 2018. https://www.ictinc.ca/blog/12-common-mistakes-in-first-nationconsultation.

Joseph, B. "A Look at Indigenous Relations in Canada for 2018 and Beyond." Indigenous Corporate Training Inc. January 11, 2018. Accessed March 23, 2018. https://www.ictinc.ca/blog/a-look-at-indigenous-relations-incanada-for-2018-and-beyond.

Leroy, S., R. Dobell, T. Dorcey, and J. Tansey. 2003. "Public Process and the Creation of the Race Rocks Marine Protected Area." In Georgia Basin/Puget Sound Research Conference, 1-12.

Lewis, J. L., and S. R. J. Sheppard. 2006. "Culture and Communication: Can Landscape Visualization Improve Forest Management Consultation with Indigenous Communities ?" Landscape and Urban Planning 77 (3): 291 313. 
Maritime Aboriginal Peoples Council. 2014. "Case Study on Consultation , Accommodation and Cooperation with Aboriginal Peoples Undertaken by Environment Canada in Regard to the Boreal Woodland Caribou , and by Fisheries and Oceans Canada in Regard to the Inner Bay of Fundy Atlantic Salmon and American Eel; and Identification Gaps and Suggestions to Increase the level of Aboriginal Participation in the Species at Risk Act."

Martín-López, B., C. Montes, and J. Benayas. 2007. "The Non-Economic Motives behind the Willingness to Pay for Biodiversity Conservation." Biological Conservation 139 (1-2): 67-82.

Mooers, A. Ø., L. R. Prugh, M. Festa-Bianchet, and J. A. Hutchings. 2007. "Biases in Legal Listing under Canadian Endangered Species Legislation." Conservation Biology 21 (3): 572-75.

Mooers, A. Ø., D. F. Doak, C. S. Findlay, D. M. Green, C. Grouios, L. L. Manne, A. Rashvand, M. A. Rudd, and J. Whitton. 2010. "Science, Policy, and Species at Risk in Canada." BioScience 60 (10): 843-49.

Moore, M., S. Von Der Porten, and H. Castleden. 2017. "Consultation Is Not Consent: Hydraulic Fracturing and Water Governance on Indigenous Lands in Canada." WIREs Water 4: 1-15.

Natural Resources Canada. (2014). Aboriginal Lands of Canada [WWW Document]. URL http://geogratis.gc.ca/api/en/nrcan-rncan/esssst/815dd99d-4fbd-47cc-be02-7ad4b03a23ec.htm|\#distribution

Raymond, C. V., L. Wen, S. J. Cooke, and J. R. Bennett. 2018. "National Attention to Endangered Wildlife Is Not Affected by Global Endangerment: A Case Study of Canada's Species at Risk Program." Environmental Science and Policy 84: 74-79.

Raymond, H. 2007. "The Ecologically Noble Savage Debate." Annual Review of Anthropology 36 (1): 177-90.

Redford, K. H. 1991. "The Ecologically Noble Savage." Cultural Survival Quarterly 15 (1): 46.

Smith, M. A. 2015. "A Reflection on First Nations in Their Boreal Homelands in Ontario: Between a Rock and a Caribou." Conservation and Society 13 (1): 23.

Urban Aboriginal Peoples Study. 2011. Regina Report. [online] Toronto: Environics Institute, p.37. Available at: 
http://www.uaps.ca/wpcontent/uploads/2010/02/UAPS-Regina-FinalReport2.pdf [Accessed 7 Feb. 2018].

Walker, P. 2001. "Journeys around the medicine wheel: A story of indigenous research in a western University." The Australian Journal of Indigenous Education, 29 (2): 18-21.

Zig Zag "War of the Words: Chiefs Issue Ultimatums as Grassroots Dance in Circles." Warrior Publications. January 04, 2013. Accessed May 02, 2018. https://warriorpublications.wordpress.com/2013/01/03/war-of-the-wordschiefs-issue-ultimatums-as-grassroots-dance-in-circles/. 


\section{Appendix A: Scoring System}

\section{Score of 0: No consultation}

- No mention at all

- "Numerous aboriginal groups within the range of the species were informed of the strategy and opportunity for involvement..." Not followed by any mention on if comments were received or not.

○ "No comments received" = Declined involvement

- Statements on goals for future involvement do not indicate current involvement/co-management, and so would receive a 0.

Low Score (1): Very vague statements on involvement with no specific Indigenous groups named, and no specific details on what level or type of involvement they had in the document.

- "[To the extent possible], it has been prepared in cooperation with Aboriginal Groups/First Nations..."

- "Acknowledgement and thanks is given to all parties that provided advice and input including various aboriginal organizations..."

- "Consultations have been held with Aboriginal communities."

- "Letters were mailed, e-mailed and faxed to First Nations Organizations in the species' range requesting input on this draft action plan...comments were received..."

- Does not state the specific names of a nation or person.

- "First Nations (not listed by name) contributed knowledge/perspectives to plan."

- "A draft version of this recovery strategy was also submitted to First Nations communities..."

- "Acknowledgement and thanks goes to First Nation consultation"

Low-medium Score (2): Specific Indigenous groups are named, though their exact role in the document creation maybe small or not explicitly stated.

- "To the extent possible, it has been prepared with (specific Indigenous group name here)"

- Acknowledgement/thanks is given to Indigenous group/individual by name

- "Letters, plain language summaries of the recovery strategy and factsheets were sent to the following Indigenous groups: (Specific bands/tribes named here). Comments were received from (Specific bands/tribes named here)."

- "Indigenous groups (listed by band or individual name) attended workshops regarding the species at risk..."

- "Indigenous groups (listed by band or individual name) were represented on a committee that was engaged during the draft of the action plan." 
Medium Score (3): Specific Indigenous groups (specifically named) are mentioned as assisting in preparation of document, and the information provided by Indigenous groups is explicitly listed.

- "Prepared in cooperation with (specific Indigenous group name here)." *

- "Meetings were held with (specific Indigenous group name(s) here)."

- "Knowledge was shared by Aboriginal Traditional Knowledge holders and Aboriginal communities on...life history, habitat use, population status, threats and conservation measures, and this information has been integrated, to the extent possible, into the development of this recovery strategy"

- Information on local activities and perspectives, the species' biology, and/or current management was provided by [specific nation/band/tribe].

Medium-high Score (4): Indigenous groups or individuals are listed as reviewers/editors or personal contacts in the formation of the document.

- "Additional revision to the document made based on comments and edits by (Specific Indigenous group(s) here)."

- Reviewers/co-developers of plan: (Indigenous group(s) mentioned by name here)

- Indigenous individuals/group listed as technical advisors in document preparation.

- Indigenous group/individuals are listed as personal communications.

Highest Scores (5): Indigenous groups or individuals listed as co-authors or editors, representing the highest level of collaboration/cooperation in the formation of the document.

- Individuals are listed as contributors/coauthors, or editors

- Indigenous groups are listed as responsible agencies and jurisdiction.

- Indigenous groups or individuals listed as recovery team/management team members (often considered co-authors of report). 


\section{Appendix B: Additional Figures and Analysis}

Table A1. Percentage of Indigenous declined involvement by region.

\begin{tabular}{|c|c|}
\hline Region & Declined Involvement (\%) \\
\hline Central & 5.56 \\
\hline Eastern & 5.56 \\
\hline Northern/Arctic & 4.0 \\
\hline Ontario & 2.19 \\
\hline Quebec & 4.41 \\
\hline Western & 8.39 \\
\hline
\end{tabular}




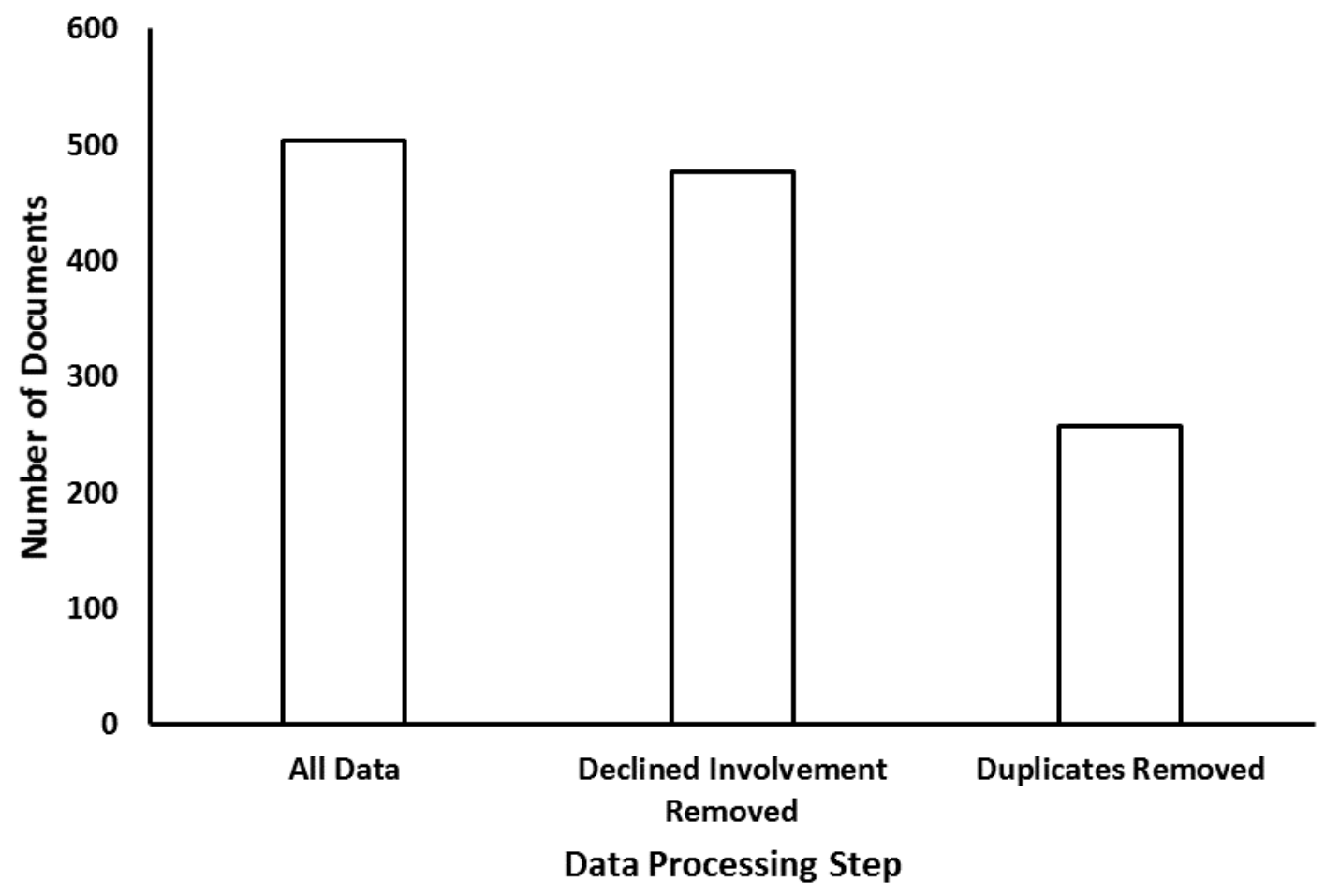

Figure A1. Number of recovery strategies and management plans included in each stage of data analysis. Data include all recovery strategies and management plans of species whose ranges overlap with Indigenous lands. Duplicates are defined as any species document that was counted more than once to represent multiple regions of species range.

Table A2. Percentage of zeros scored for recovery strategies and management plan in each regional category. Species whose ranges do not overlap with Indigenous lands and "declined involvement" zeros removed $(n=477)$.

\begin{tabular}{|c|c|}
\hline Region & Percent Zeros \\
\hline Central & 76.5 \\
Eastern & 46.4 \\
Northern/Arctic & 33.3 \\
Ontario & 38.1 \\
Quebec & 56.3 \\
Western & 57.3 \\
\hline
\end{tabular}


Table A3. Percentage of zeros scored for recovery strategies and management plans in each taxonomic category. Species whose ranges do not overlap with Indigenous lands and "declined involvement" zeros removed $(n=477)$.

\begin{tabular}{|c|c|}
\hline Taxon & Percent Zeros \\
\hline \multirow{10}{*}{$\begin{array}{c}\text { Amphibian } \\
\text { Arthropod } \\
\text { Bird } \\
\text { Fish } \\
\text { Lichen } \\
\text { Mammal } \\
\text { Mollusc } \\
\text { Moss } \\
\text { Plant } \\
\text { Reptile }\end{array}$} & 75.0 \\
\hline & 73.5 \\
\hline & 52.0 \\
\hline & 27.3 \\
\hline & 66.7 \\
\hline & 31.3 \\
\hline & 50.0 \\
\hline & 100.0 \\
\hline & 54.5 \\
\hline & 38.5 \\
\hline
\end{tabular}

Table A4. Results of a permutation based ANOVA testing differences in mean scores, showing the relationship between region and document type (management plan and recovery strategy).

\begin{tabular}{r|llll} 
& DF & Sum Sq & Mean Sq & Probability \\
\hline Region & 5 & 55.84 & 11.17 & $<2 \mathrm{e}-16$ \\
Document Type & 1 & 5.27 & 5.27 & 0.098 \\
$\begin{array}{r}\text { Region } \times \\
\text { Document Type }\end{array}$ & 5 & 19.04 & 3.81 & 0.18 \\
Residuals & 465 & 2.13 & 2.13 &
\end{tabular}


Table A5. Results of a permutation based ANOVA testing differences in mean scores, showing the relationship between taxonomic category and document type (management plan and recovery strategy).

\begin{tabular}{|c|c|c|c|c|}
\hline & $D F$ & Sum Sq & Mean Sq & Probability \\
\hline Taxon & 9 & 109.9 & 12.21 & $<2$ e-16 \\
\hline Document Type & 1 & 20.32 & 20.32 & $<2$ e-16 \\
\hline $\begin{array}{r}\text { Taxon } x \\
\text { Document Type }\end{array}$ & 9 & 12.50 & 1.39 & 0.73 \\
\hline Residuals & 457 & 943.71 & 2.065 & \\
\hline
\end{tabular}

Table A6. Results of a permutation based ANOVA testing differences in mean scores, showing the relationship between taxonomic category and region.

\begin{tabular}{r|llll} 
& DF & Sum Sq & Mean Sq & Probability \\
\hline Taxon & 9 & 64.42 & 7.16 & $<2 \mathrm{e}-16$ \\
Region & 5 & 32.64 & 6.53 & 0.0028 \\
Taxon x Region & 38 & 86.26 & 2.27 & 0.38 \\
& & & &
\end{tabular}


Table A7. Results of a permutation based ANOVA testing for differences in mean scores among regional categories. Differences among individual regional pairs are shown in figure 2 .

\begin{tabular}{r|llll}
\multicolumn{2}{r}{ DF } & Sum Sq & Mean $\mathrm{Sq}$ & Probability \\
\hline Region & 5 & 65.1 & 13.021 & $<2.2 \mathrm{e}-16$ \\
Residuals & 471 & 1032.5 & 2.19 &
\end{tabular}

Table A8. Results of a permutation based ANOVA testing differences in mean scores, among taxonomic categories. Differences among individual taxonomic pairs are shown in figure 3.

\begin{tabular}{r|llll}
\multicolumn{2}{r}{ DF } & Sum Sq & Mean Sq & Probability \\
\hline Taxon & 9 & 117.84 & 13.093 & $<2.2 \mathrm{e}-16$ \\
Residuals & 467 & 979.73 & 2.098 &
\end{tabular}




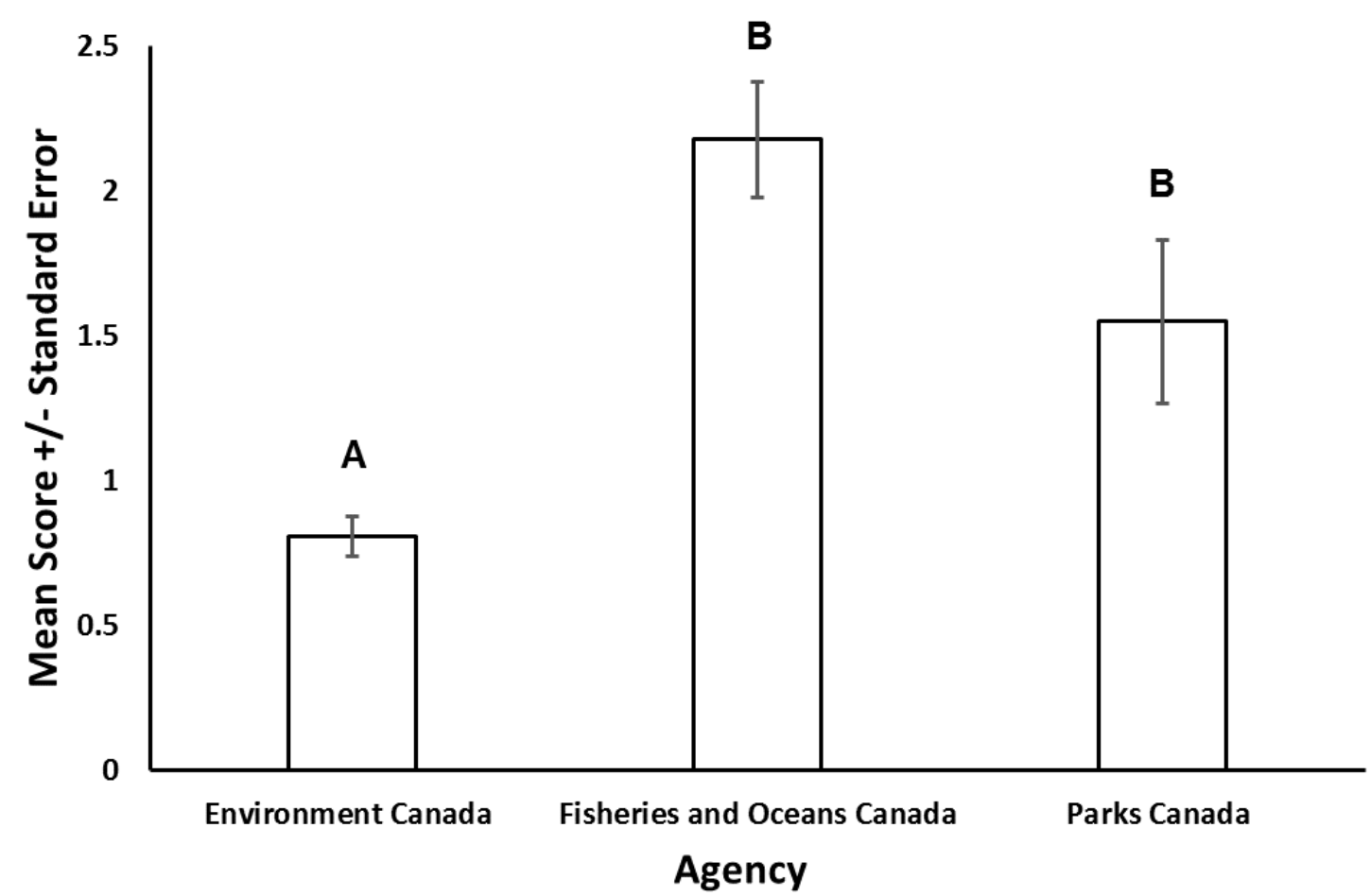

Figure A2. Mean score for evidence of Indigenous involvement in recovery strategies and management plans by agency ( \pm standard error (SE)).. The letters above each bar represent groupings based on significant differences in pairwise permutation tests. Environment and Climate Change Canada $(n=353)$, Fisheries and Oceans Canada $(n=73)$, Parks Canada $(n=51)$.

Table A9. Results of a permutation based ANOVA showing the relationship between score and agency. Agency was not included in main model as many taxonomic groups are not represented by certain agencies. Differences among individual agency pairs are shown in figure A2.

\begin{tabular}{r|llll} 
& DF & Sum Sq & Mean Sq & Probability \\
\hline Agency & 2 & 125.35 & 62.68 & $<2.2$ e-16 \\
Residuals & 474 & 972.21 & 2.051 &
\end{tabular}


Table A10. Results of a permutation based ANOVA testing differences in mean scores, showing the relationship between region and responsible agency.

\begin{tabular}{r|llll} 
& DF & Sum Sq & Mean Sq & Probability \\
\hline Agency & 2 & 55.41 & 27.70 & $<2.2 \mathrm{e}-16$ \\
Region & 5 & 50.73 & 10.15 & $<2.2 \mathrm{e}-16$ \\
$\begin{array}{r}\text { Agency } \times \\
\text { Region }\end{array}$ & 10 & 85.95 & 8.59 & $<2.2 \mathrm{e}-16$ \\
Residuals & 459 & 835.67 & 1.82 &
\end{tabular}

Table A11. Results of a pairwise permutation test showing significant differences between groupings of responsible agencies and regions.

\begin{tabular}{r|rr}
\multicolumn{1}{c}{ Comparison } & \multicolumn{1}{c}{ Stat } & Adjusted P Value \\
\hline ECCC Central vs. ECCC East & -3.001 & 0.012 \\
ECCC Central vs. ECCC North & -5.37 & $1.52 \mathrm{E}-06$ \\
ECCC Central vs. ECCC Ontario & -4.13 & 0.00028 \\
ECCC Central vs. ECCC Quebec & -2.76 & 0.023 \\
ECCC Central vs. ECCC West & -3.30 & 0.0055 \\
ECCC Central vs. DFO Central & 5.35 & $1.52 \mathrm{E}-06$ \\
ECCC Central vs. DFO East & 6.30 & $1.48 \mathrm{E}-08$ \\
ECCC Central vs. DFO North & 2.7 & 0.027 \\
ECCC Central vs. DFO Ontario & 5.35 & $1.52 \mathrm{E}-06$ \\
ECCC Central vs. DFO Quebec & 3.64 & 0.0017 \\
ECCC Central vs. DFO West & 6.72 & $2.55 \mathrm{E}-09$ \\
ECCC Central vs. PC Central & -1.59 & 0.26 \\
ECCC Central vs. PC East & -6.63 & $2.55 \mathrm{E}-09$ \\
ECCC Central vs. PC North & -1.51 & 0.26 \\
ECCC Central vs. PC Ontario & -6.25 & $1.62 \mathrm{E}-08$ \\
ECCC Central vs. PC Quebec & 0.64 & 0.66 \\
ECCC Central vs. PC West & -2.63 & 0.031 \\
ECCC East vs. ECCC North & -3.047 & 0.011 \\
ECCC East vs. ECCC Ontario & -0.58 & 0.71 \\
ECCC East vs. ECCC Quebec & 0.72 & 0.61 \\
ECCC East vs. ECCC West & -1.07 & 0.46
\end{tabular}




\begin{tabular}{r|rr} 
ECCC East vs. DFO Central & 2.52 & 0.042 \\
ECCC East vs. DFO East & 4.26 & 0.00018 \\
ECCC East vs. DFO North & 0.85 & 0.57 \\
ECCC East vs. DFO Ontario & 3.12 & 0.0087 \\
ECCC East vs. DFO Quebec & 1.47 & 0.27 \\
ECCC East vs. DFO West & 4.48 & $7.21 \mathrm{E}-05$ \\
ECCC East vs. PC Central & 0.048 & 0.97 \\
ECCC East vs. PC East & -4.24 & 0.00018 \\
ECCC East vs. PC North & -0.24 & 0.88 \\
ECCC East vs. PC Ontario & -4.25 & 0.00018 \\
ECCC East vs. PC Quebec & 0.95 & 0.51 \\
ECCC East vs. PC West & -0.41 & 0.78 \\
ECCC North vs. ECCC Ontario & 3.57 & 0.0022 \\
ECCC North vs. ECCC Quebec & 3.93 & 0.00059 \\
ECCC North vs. ECCC West & 1.89 & 0.15 \\
ECCC North vs. DFO Central & 0.41 & 0.78 \\
ECCC North vs. DFO East & 1.56 & 0.26 \\
ECCC North vs. DFO North & -0.53 & 0.71 \\
ECCC North vs. DFO Ontario & 0.098 & 0.95 \\
ECCC North vs. DFO Quebec & -0.74 & 0.60 \\
ECCC North vs. DFO West & 1.12 & 0.43 \\
ECCC North vs. PC Central & 1.52 & 0.26 \\
ECCC North vs. PC East & -2.27 & 0.079 \\
ECCC North vs. PC North & 0.53 & 0.71 \\
ECCC North vs. PC Ontario & -1.46 & 0.27 \\
ECCC North vs. PC Quebec & 1.51 & 0.26 \\
ECCC North vs. PC West & 1.98 & 0.13 \\
ECCC Ontario vs. ECCC Quebec & 1.55 & 0.26 \\
ECCC Ontario vs. ECCC West & -1.009 & 0.49 \\
ECCC Ontario vs. DFO Central & 2.67 & 0.028 \\
ECCC Ontario vs. DFO East & 5.28 & 0.58 \\
ECCC Ontario vs. DFO North & 0.80 & 0.27 \\
ECCC Ontario vs. DFO Ontario & 3.71 & $1.25 \mathrm{E}-06$ \\
ECCC Ontario vs. DFO Quebec & 1.50 & 0.84 \\
ECCC Ontario vs. DFO West & 5.46 & 0.191 \\
ECCC Ontario vs. PC Central & 0.32 & -06 \\
ECCC Ontario vs. PC East & -5.064 & -0.15 \\
ECCC Ontario vs. PC North & -0.15 \\
\hline
\end{tabular}




\begin{tabular}{|c|c|c|}
\hline ECCC Ontario vs. PC Ontario & -5.32 & 1.63E-06 \\
\hline ECCC Ontario vs. PC Quebec & 1.19 & 0.40 \\
\hline ECCC Ontario vs. PC West & -0.11 & 0.94 \\
\hline ECCC Quebec vs. ECCC West & -1.74 & 0.20 \\
\hline ECCC Quebec vs. DFO Central & 3.43 & 0.0035 \\
\hline ECCC Quebec vs. DFO East & 5.17 & 2.81E-06 \\
\hline ECCC Quebec vs. DFO North & 1.34 & 0.32 \\
\hline ECCC Quebec vs. DFO Ontario & 3.98 & 0.00050 \\
\hline ECCC Quebec vs. DFO Quebec & 2.14 & 0.096 \\
\hline ECCC Quebec vs. DFO West & 5.46 & $1.25 \mathrm{E}-06$ \\
\hline ECCC Quebec vs. PC Central & -0.30 & 0.85 \\
\hline ECCC Quebec vs. PC East & -5.25 & $1.96 \mathrm{E}-06$ \\
\hline ECCC Quebec vs. PC North & -0.50 & 0.73 \\
\hline ECCC Quebec vs. PC Ontario & -5.14 & $3.06 \mathrm{E}-06$ \\
\hline ECCC Quebec vs. PC Quebec & 1.015 & 0.49 \\
\hline ECCC Quebec vs. PC West & -0.99 & 0.49 \\
\hline ECCC West vs. DFO Central & 1.31 & 0.33 \\
\hline ECCC West vs. DFO East & 3.19 & 0.0072 \\
\hline ECCC West vs. DFO North & 0.26 & 0.87 \\
\hline ECCC West vs. DFO Ontario & 2.021 & 0.12 \\
\hline ECCC West vs. DFO Quebec & 0.57 & 0.71 \\
\hline ECCC West vs. DFO West & 3.24 & 0.0063 \\
\hline ECCC West vs. PC Central & 0.49 & 0.73 \\
\hline ECCC West vs. PC East & -2.96 & 0.013 \\
\hline ECCC West vs. PC North & 0.033 & 0.97 \\
\hline ECCC West vs. PC Ontario & -3.27 & 0.0059 \\
\hline ECCC West vs. PC Quebec & 0.84 & 0.57 \\
\hline ECCC West vs. PC West & 0.46 & 0.75 \\
\hline DFO Central vs. DFO East & -0.70 & 0.63 \\
\hline DFO Central vs. DFO North & 0.76 & 0.60 \\
\hline DFO Central vs. DFO Ontario & 0.33 & 0.84 \\
\hline DFO Central vs. DFO Quebec & 0.85 & 0.57 \\
\hline DFO Central vs. DFO West & -0.25 & 0.88 \\
\hline DFO Central vs. PC Central & 1.41 & 0.29 \\
\hline DFO Central vs. PC East & -1.98 & 0.13 \\
\hline DFO Central vs. PC North & 1.12 & 0.43 \\
\hline DFO Central vs. PC Ontario & -0.56 & 0.71 \\
\hline DFO Central vs. PC Quebec & 1.89 & 0.15 \\
\hline
\end{tabular}




\begin{tabular}{|c|c|c|}
\hline DFO Central vs. PC West & 1.58 & 0.26 \\
\hline DFO East vs. DFO North & 1.25 & 0.36 \\
\hline DFO East vs. DFO Ontario & 1.46 & 0.27 \\
\hline DFO East vs. DFO Quebec & 1.79 & 0.18 \\
\hline DFO East vs. DFO West & 0.86 & 0.57 \\
\hline DFO East vs. PC Central & 2.20 & 0.091 \\
\hline DFO East vs. PC East & -1.48 & 0.27 \\
\hline DFO East vs. PC North & 1.005 & 0.49 \\
\hline DFO East vs. PC Ontario & 0.16 & 0.91 \\
\hline DFO East vs. PC Quebec & 1.92 & 0.15 \\
\hline DFO East vs. PC West & 2.99 & 0.012 \\
\hline DFO North vs. DFO Ontario & -0.56 & 0.71 \\
\hline DFO North vs. DFO Quebec & -0.053 & 0.97 \\
\hline DFO North vs. DFO West & -1.16 & 0.41 \\
\hline DFO North vs. PC Central & 0.47 & 0.75 \\
\hline DFO North vs. PC East & -1.55 & 0.26 \\
\hline DFO North vs. PC North & 0.15 & 0.91 \\
\hline DFO North vs. PC Ontario & -1.17 & 0.40 \\
\hline DFO North vs. PC Quebec & 0.82 & 0.58 \\
\hline DFO North vs. PC West & 0.45 & 0.75 \\
\hline DFO Ontario vs. DFO Quebec & 0.80 & 0.58 \\
\hline DFO Ontario vs. DFO West & -0.99 & 0.49 \\
\hline DFO Ontario vs. PC Central & 1.53 & 0.26 \\
\hline DFO Ontario vs. PC East & -2.16 & 0.096 \\
\hline DFO Ontario vs. PC North & 0.53 & 0.71 \\
\hline DFO Ontario vs. PC Ontario & -1.36 & 0.31 \\
\hline DFO Ontario vs. PC Quebec & 1.48 & 0.27 \\
\hline DFO Ontario vs. PC West & 2.047 & 0.12 \\
\hline DFO Quebec vs. DFO West & -1.67 & 0.22 \\
\hline DFO Quebec vs. PC Central & 0.75 & 0.60 \\
\hline DFO Quebec vs. PC East & -2.098 & 0.10 \\
\hline DFO Quebec vs. PC North & 0.21 & 0.89 \\
\hline DFO Quebec vs. PC Ontario & -1.73 & 0.20 \\
\hline DFO Quebec vs. PC Quebec & 1.004 & 0.49 \\
\hline DFO Quebec vs. PC West & 0.82 & 0.58 \\
\hline DFO West vs. PC Central & 2.36 & 0.064 \\
\hline DFO West vs. PC East & -2.24 & 0.083 \\
\hline DFO West vs. PC North & 0.98 & 0.49 \\
\hline
\end{tabular}




\begin{tabular}{r|rr} 
DFO West vs. PC Ontario & -0.68 & 0.64 \\
DFO West vs. PC Quebec & 2.15 & 0.096 \\
DFO West vs. PC West & 3.12 & 0.0087 \\
PC Central vs. PC East & -2.14 & 0.096 \\
PC Central vs. PC North & -0.15 & 0.91 \\
PC Central vs. PC Ontario & -2.17 & 0.096 \\
PC Central vs. PC Quebec & 0.53 & 0.71 \\
PC Central vs. PC West & -0.23 & 0.88 \\
PC East vs. PC North & 1.41 & 0.29 \\
PC East vs. PC Ontario & 1.52 & 0.26 \\
PC East vs. PC Quebec & 1.73 & 0.20 \\
PC East vs. PC West & 2.92 & 0.014 \\
PC North vs. PC Ontario & -0.92 & 0.52 \\
PC North vs. PC Quebec & 1.41 & 0.29 \\
PC North vs. PC West & 0.077 & 0.96 \\
PC Ontario vs. PC Quebec & 1.86 & 0.16 \\
PC Ontario vs. PC West & 2.99 & 0.012 \\
PC Quebec vs. PC West & -0.75 & 0.60
\end{tabular}




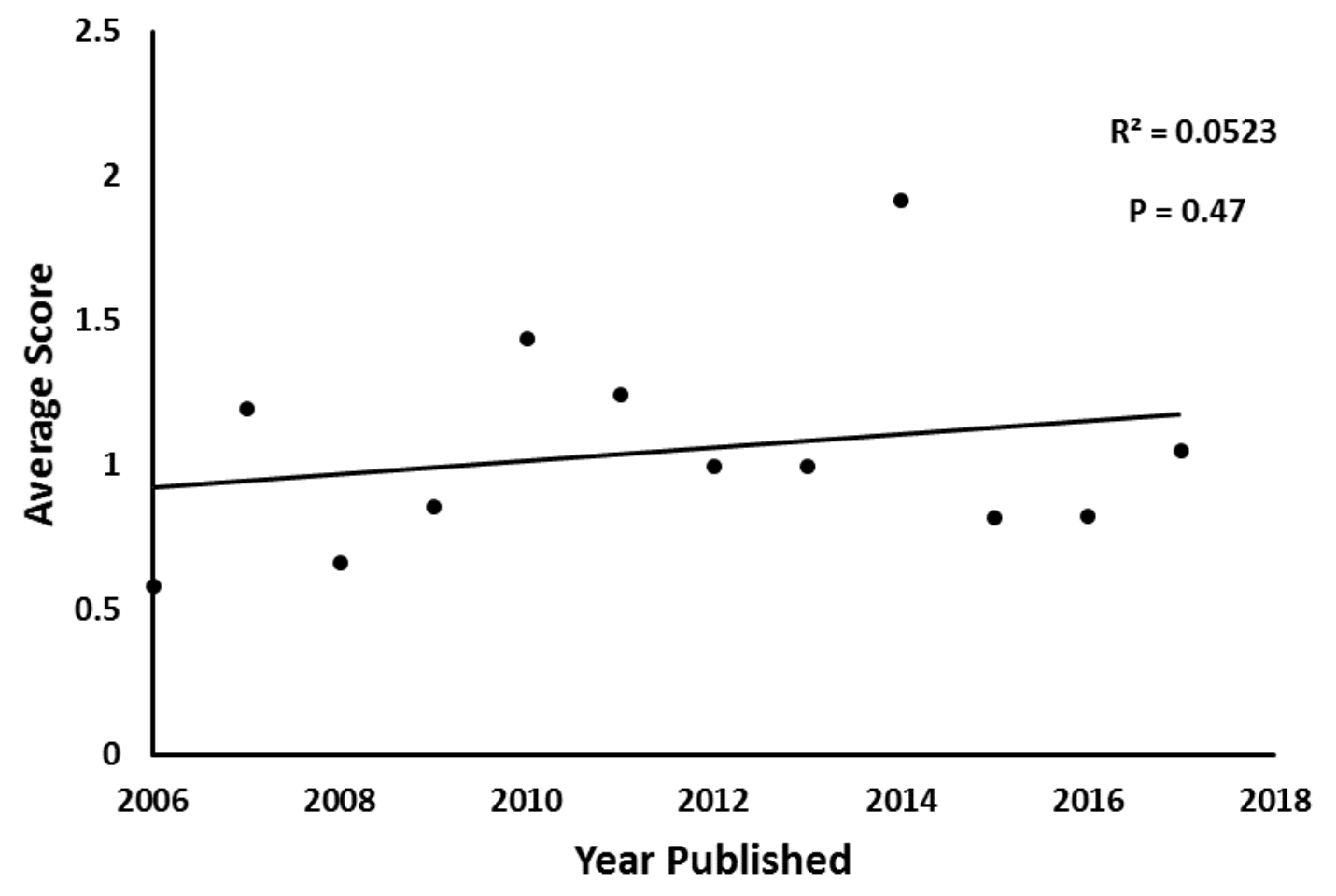

Figure A3. Scatter plot with trend line showing average score of recovery documents versus the year they were published, starting with the first documents published in 2006. $R^{2}$ and $p$-value based on an ordinary least squares regression shown within chart.

Table A12. Results of a permutation based ANOVA testing differences in mean scores, showing the relationship between region and taxonomic group after all multi-regional plans had been eliminated.

\begin{tabular}{r|llll} 
& DF & Sum Sq & Mean Sq & Probability \\
\hline Taxon & 9 & 36.82 & 4.091 & 0.087 \\
Region & 5 & 20.83 & 4.16 & 0.14 \\
Taxon $\times$ & 26 & 71.82 & 2.76 & 0.19 \\
Region & & & & \\
Residuals & 216 & 494.33 & 2.29 &
\end{tabular}




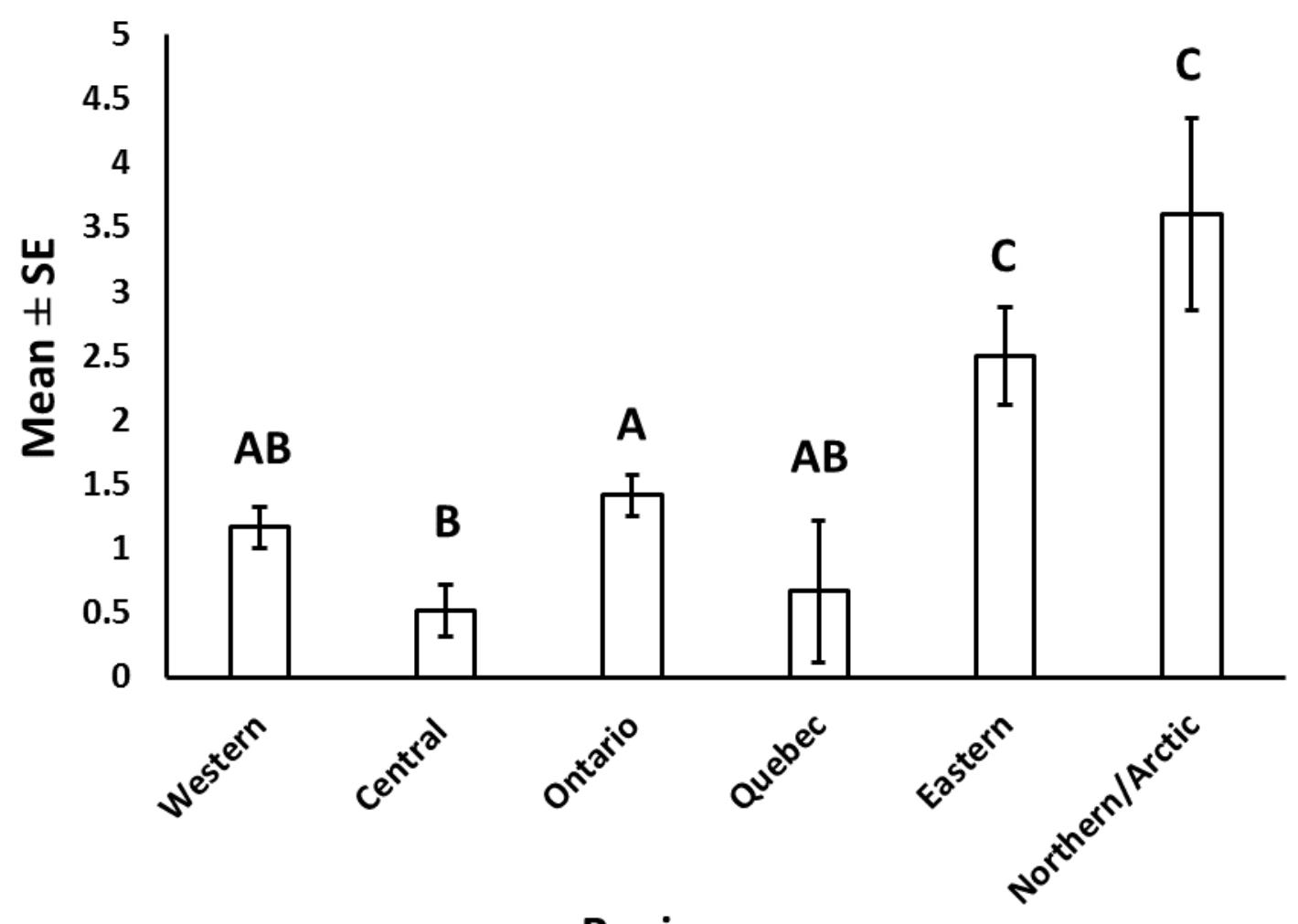

Region

Figure A4. Mean score for evidence of Indigenous involvement in recovery strategies and management plans by region ( \pm standard error (SE))., after all multi-regional plans had been eliminated. The letters above each bar represent groupings based on significant differences in pairwise permutation tests. Species whose ranges do not overlap with Indigenous lands removed, "declined involvement" species removed. Western region (Pacific Ocean and British Columbia: $n=104$ ), central region (Albert, Saskatchewan and Manitoba: $n=35$ ), Ontario $(n=80)$, Quebec $(n=9)$, eastern region (Nova Scotia, New Brunswick, Prince Edward Island, Newfoundland and Labrador, and the Atlantic Ocean: n= 24), northern/arctic region (Yukon, Nunavut, Northwest Territories, and the Arctic Ocean: $n=5)$. 
Table A13. Results of a permutation based ANOVA testing differences in mean scores, among regional categories after all multi-regional plans had been eliminated. Differences among individual regional pairs are shown in figure A4.

\begin{tabular}{r|llll} 
& DF & Sum Sq & Mean Sq & Probability \\
\hline $\begin{array}{r}\text { Region } \\
\text { Residuals }\end{array}$ & 5 & 88.96 & 17.79 & $<2.2$ e-16 \\
& 251 & 621.36 & 2.48 &
\end{tabular}

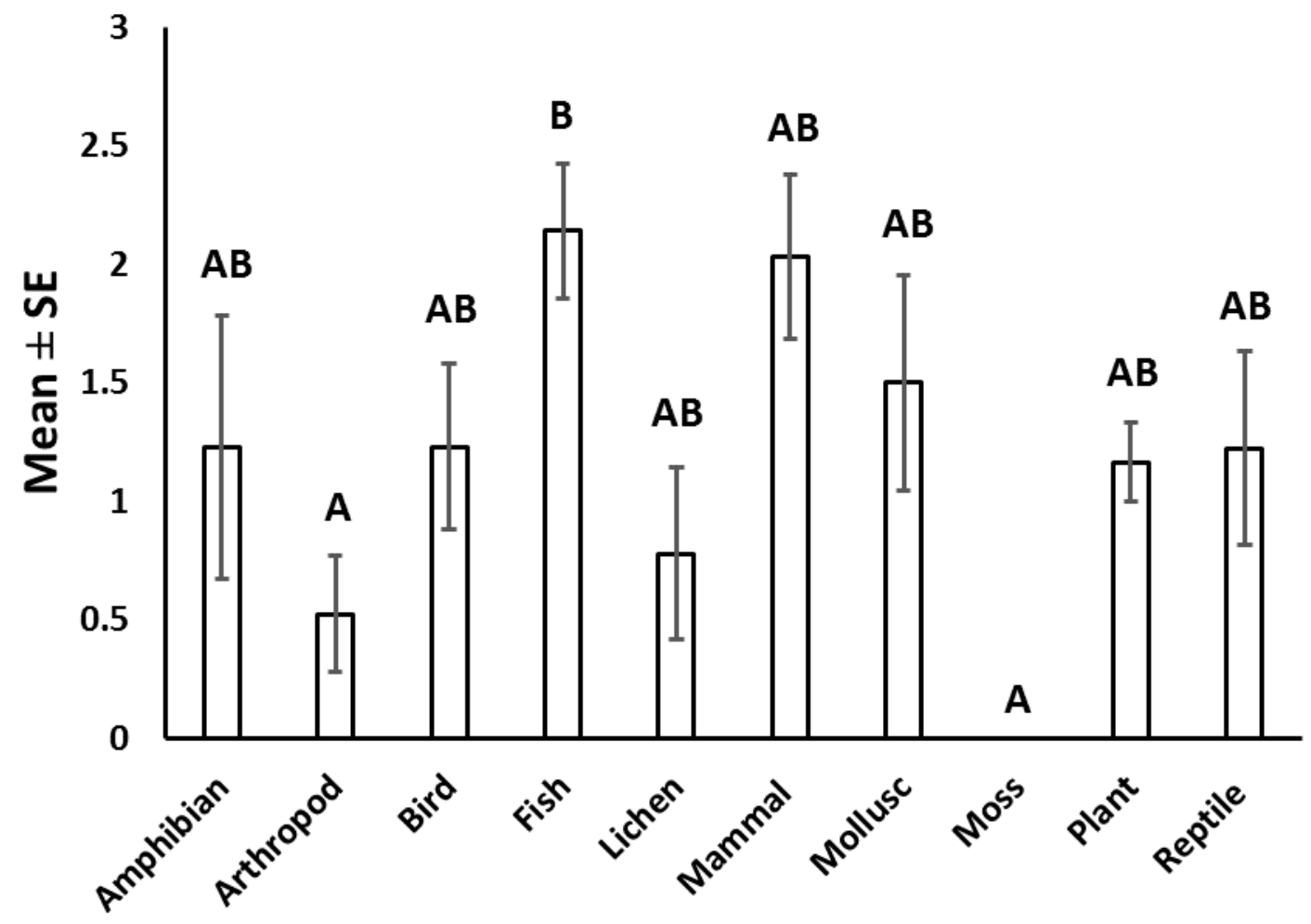

Taxon

Figure A5. Mean score for evidence of Indigenous involvement in recovery strategies and management plans by taxonomic category ( \pm standard error $(\mathrm{SE})$ ).. The letters above each bar represent groupings based on significant differences in pairwise permutation tests. Species whose ranges do not overlap with Indigenous lands removed, "declined involvement" species removed, and duplicates from multi-regional species removed. Amphibians $(n=13)$, arthropods $(n=21)$, birds $(n=26)$, fish $(n=28)$, lichens $(n=9)$, mammals $(n=33)$, molluscs $(n=14)$, mosses $(n=10)$, plants $(n=85)$, reptiles $(n=18)$. 
Table A14. Results of a permutation based ANOVA testing differences in mean scores among taxonomic categories after all multi-regional plans had been eliminated. Differences among individual taxonomic pairs are shown in figure A5.

\begin{tabular}{r|llll} 
& DF & Sum $S q$ & Mean $S q$ & Probability \\
\hline Taxon & 9 & 71.91 & 7.99 & 0.0012 \\
Residuals & 247 & 638.42 & 2.58 &
\end{tabular}

